\title{
Subantarctic and Polar Fronts of the Antarctic Circumpolar Current and Southern Ocean Heat and Freshwater Content Variability: A View from Argo*,+
}

\author{
DONATA GigLio \\ Joint Institute for the Study of the Atmosphere and Ocean, University of Washington, Seattle, Washington \\ GREGORY C. JOHNSON \\ NOAA/Pacific Marine Environmental Laboratory, Seattle, Washington
}

(Manuscript received 17 July 2015, in final form 6 November 2015)

\begin{abstract}
Argo profiling floats initiated a revolution in observational physical oceanography by providing numerous, high-quality, global, year-round, in situ (0-2000 dbar) temperature and salinity observations. This study uses Argo's unprecedented sampling of the Southern Ocean during 2006-13 to describe the position of the Antarctic Circumpolar Current's Subantarctic and Polar Fronts, comparing and contrasting two different methods for locating fronts using the same dataset. The first method locates three fronts along dynamic height contours, each corresponding to a local maximum in vertically integrated shear. The second approach locates the fronts using specific features in the potential temperature field, following Orsi et al. Results from the analysis of Argo data are compared to those from Orsi et al. and other more recent studies. Argo spatial resolution is not adequate to resolve annual and interannual movements of the fronts on a circumpolar scale since they are on the order of $1^{\circ}$ latitude (Kim and Orsi), which is smaller than the resolution of the gridded product analyzed. Argo's four-dimensional coverage of the Southern Ocean equatorward of $\sim 60^{\circ} \mathrm{S}$ is used to quantify variations in heat and freshwater content there with respect to the time-mean front locations. These variations are described during 2006-13, considering both pressure and potential density ranges (within different water masses) and relations to wind forcing (Ekman upwelling and downwelling).
\end{abstract}

\section{Introduction}

Over the last three decades, the Southern Hemisphere climate has experienced dramatic changes: growth of the ozone hole (Hofmann et al. 1997; WMO 2011; http:// www.nature.com/nature/focus/ozonehole/), increased melting of the West Antarctic Ice Sheet (Ding et al. 2011; Rignot et al. 2014), overall thinning of the Antarctic ice

\footnotetext{
* Supplemental information related to this paper is available at the Journals Online website: http://dx.doi.org/10.1175/JPO-D-150131.s1.

${ }^{+}$Joint Institute for Marine and Atmospheric Research Contribution Number 2477 and Pacific Marine Environmental Laboratory Contribution Number 4350.

Corresponding author address: Donata Giglio, Joint Institute for the Study of the Atmosphere and Ocean, University of Washington, Box 355672, Seattle, WA 98195.

E-mail: dgiglio@uw.edu
}

shelf (Paolo et al. 2015), stronger winds (Marshall 2003; Thompson et al. 2011), and ocean warming (Gille 2008; Sutton and Roemmich 2011; Roemmich et al. 2015). The Southern Ocean warming and freshening of water masses (Böning et al. 2008; Johnson et al. 2008; Purkey and Johnson 2010, 2013; Meijers et al. 2011) may be related to regional trends in sea ice extent (Holland and Kwok 2012) or ice sheet melt (Jacobs and Giulivi 2010) and may also drive ice sheet melting by ocean advection of heat (Rignot et al. 2013; Schmidtko et al. 2014; Alley et al. 2015). Because of its large heat capacity and influence on the meridional overturning circulation (MOC), the Southern Ocean is not only key for heat and freshwater redistribution in the global climate system (Lumpkin and Speer 2007; Marshall and Speer 2012; Watson et al. 2014), but also for the global atmosphere-ocean carbon budget (Sabine 2004; Boutin et al. 2008; Le Quéré et al. 2009; Ito et al. 2010; Sallée et al. 2012). A quarter of all anthropogenic $\mathrm{CO}_{2}$ emissions have been captured in the Southern Ocean, with a main contribution by 
transformation of water masses within the Antarctic Circumpolar Current and their subsequent sinking below the surface (Sabine 2004; Ito et al. 2010).

The Antarctic Circumpolar Current (ACC), the world's largest current, is the main feature of the Southern Ocean and is dynamically connected with the MOC, which ventilates deep and bottom portions of the Pacific, Atlantic, and Indian Oceans (Lumpkin and Speer 2007; Johnson 2008; Marshall and Speer 2012). Also, the ACC circulation blends together water masses formed in different basins (Rintoul et al. 2001; Van Sebille et al. 2013). The ACC is not a smooth, large-scale flow. Rather, most of its transport is concentrated in a series of well-separated fronts (Orsi et al. 1995, hereinafter OWN95; Sallée et al. 2008; Sokolov and Rintoul 2009a, b; Thompson et al. 2010; Thompson and Sallée 2012; Kim and Orsi 2014). These features separate regions with distinct temperature and salinity signatures and are associated with deep-reaching jets and subduction or upwelling of different water masses. In a landmark paper, OWN95 describe average properties of the fronts using station data from multiple synoptic transects. Three fronts are identified between the southern boundary of the ACC and the Subtropical Front to the north: the Southern ACC Front, the Polar Front, and the Subantarctic Front. Initially, the presence of multiple cores in these ACC fronts was not detected, given the coarse meridional spacing of station data, but has since been revealed (Sokolov and Rintoul 2002, 2007, 2009a; Anilkumar et al. 2006). Numerous regional analyses of the ACC frontal structure are based on in situ oceanographic profile or surface (i.e., surface drifter or satellite) data. Most common domains for these studies are in Drake Passage (Cunningham and Pavic 2007; Firing et al. 2011; Renault et al. 2011), around the Kerguelen Plateau (Sparrow et al. 1996; Belkin and Gordon 1996; Park et al. 2009, 2014; Tarakanov 2014), and along the ACC sector south of Australia and New Zealand (Belkin and Gordon 1996; Sokolov and Rintoul 2002, 2007; Budillon and Rintoul 2003). Additional analyses have been carried out south of Africa (Belkin and Gordon 1996) and in the South Atlantic (Peterson and Whitworth 1989; Boehme et al. 2008; Billany et al. 2010), Indian (Belkin and Gordon 1996; Anilkumar et al. 2015), and eastern Pacific (Tarakanov 2011) sectors of the Southern Ocean.

In addition to hydrographic data (OWN95; Böning et al. 2008), surface observations from satellites have been widely used to describe the ACC fronts on a global (circumpolar) scale (Gille 1994; Dong et al. 2006; Sallée et al. 2008; Sokolov and Rintoul 2009a,b; Thompson and Sallée 2012; Kim and Orsi 2014). Sallée et al. (2008) and Sokolov and Rintoul (2009a,b) combine the mean dynamic topography from in situ profiles (referenced to 1500 and 2500 dbar, respectively), with altimetry data to study both the time mean and variability of the fronts' location through a contour-based approach (Sokolov and Rintoul 2007, 2009a,b). The applicability of this method has been debated (Graham et al. 2012; Thompson and Sallée 2012; De Boer et al. 2013; Gille 2014). Graham et al. (2012) find that gradient maxima in the sea surface height (SSH) field are the most reliable indicator of a front's location, while using $\mathrm{SSH}$ contours can give misleading results for the temporal variability of the frontal position. Yet Chapman (2014) shows that the contour-based approach is more accurate than other methods (i.e., gradient, PDF, and wavelet methods) at all signal-to-noise ratios, when applied to a synthetic SSH field. Finally, SSH anomalies of meandering jetlike features are associated with a non-Gaussian probability density function (Thompson and Demirov 2006), allowing the study of ACC fronts with altimetry observations (Shao et al. 2015). No estimates of the mean dynamic topography are required, ensuring that any temporal variability in frontal location is unaffected by large-scale SSH changes.

Kim and Orsi (2014) find large year-to-year meridional fluctuations in frontal locations in the southeast Pacific during 1992-2011 using altimetry data and a contour-based approach (with a mean dynamic topography that combines GRACE and Argo observations). These fluctuations are related mostly to the El NiñoSouthern Oscillation (ENSO) and in part to the southern annular mode (SAM), with no apparent seasonal cycles or long-term trends detected in this region. In contrast, in the southeast Indian Ocean fronts shift to the south in summer and to the north in winter. Also, a long-term southward drift of the ACC fronts is observed in the Indian sector. This movement is hypothesized to be a response to the poleward expansion of the Indian Subtropical Gyre. Gille (2014) finds no long-term trend in the zonally averaged ACC transport latitude index [based on the (zonal) transport-weighted average latitude] from altimetry data, a weak sensitivity to the southern annular mode, and no correlation with ENSO. Also, Gille (2014) suggests that the poleward trend in SSH contours might be associated with large-scale changes in SSH due to a warming ocean more than with localized shifts in frontal positions. Recently, Shao et al. (2015) also show that the ACC as a whole and on regional spatial scales does not exhibit significant meridional trends between 1993 and 2012 and is relatively insensitive to climate mode-induced variability except in the east Pacific (where they find correlation between the basin-averaged Subantarctic and Polar Fronts' position and SAM, with a positive SAM corresponding to a 
northward shift) and south of Australia (with the Polar Front shifting southward during positive SAM).

Since the ACC fronts are linked to ocean dynamics (current strength), thermodynamics (sites of water mass transformation; OWN95), and the pattern of upwelling/ downwelling associated with the closure of the global overturning circulation (Marshall and Speer 2012), the structure of the fronts is closely related to the distribution of heat and freshwater in the Southern Ocean. Analysis of in situ data shows how coherent warming and freshening trends in the Southern Hemisphere extend deeper than $1000 \mathrm{~m}$ and are partially related to water mass changes within the ACC (Böning et al. 2008). Altimetry data, too, reveal similar changes in the ACC (Meijers et al. 2011), with diabatic processes contributing to cooling, while playing a key role in observed freshening. During 2006-13, in the upper 2000 dbar of the global ocean sampled by Argo floats, the Southern Hemisphere ocean is the main recipient of heat from global warming, with regional patterns indicating cooling south of $50^{\circ} \mathrm{S}$ in the Pacific (Roemmich et al. 2015). Multidecadal warming and/or freshening in the ACC is also reported (Aoki et al. 2005; Sprintall 2008; Naveira Garabato et al. 2009; Tarakanov 2011; Kobayashi et al. 2012; Schmidtko and Johnson 2012; Close et al. 2013; Yang and He 2014), with some exceptions related to regional dynamics, such as the influence of the Agulhas rings south of Africa (Swart and Speich 2010).

Here, we use Argo's unprecedented sampling of the Southern Ocean (Roemmich et al. 2015) during 2006-13 to describe the position of the ACC Subantarctic and Polar Fronts based on subsurface water properties. We detect fronts using two different methods and compare with results from OWN95 and other more recent studies. Argo spatial resolution is not adequate to resolve annual and interannual movements of the fronts locally, since they are on the order of $1^{\circ}$ latitude (Kim and Orsi 2014). Yet Argo four-dimensional coverage of the Southern Ocean equatorward of $\sim 60^{\circ} \mathrm{S}$ can be used to identify fronts and quantify heat and freshwater content variations in the Southern Ocean. Here, we describe changes in heat and freshwater content in the Southern Ocean (within the Argo domain) and regions in between the mean front locations during 2006-13, considering both pressure and potential density ranges (different water masses) and relations to wind forcing (Ekman upwelling and downwelling).

We describe data and methods in section 2. We find frontal locations using Argo data, comparing a dynamic height (DH) contour approach (section 3a) with a potential temperature $(\theta)$ feature-based method (section $3 b)$. We relate these results from Argo to the findings of OWN95 and more recent studies and discuss the temperature-salinity $(\theta-S)$ properties at the fronts (section 3c). Also, we analyze changes in heat and freshwater content from 2006 to 2013 in the Southern Ocean (within the Argo domain) and for different regions in between fronts, discussing the relation between $\theta$ and $S$ variability and wind forcing (section 4$)$. We summarize and conclude in section 5 .

\section{Data and methods}

\section{a. Data}

Argo temperature and salinity profiles (Roemmich et al. 2009) provide global, in situ (0 - 2000 dbar) ocean observations, except on continental shelves, in marginal seas, and, until recently, seasonally ice-covered regions (Klatt et al. 2007), with unprecedented sampling of the Southern Ocean. We use objectively mapped monthly fields (Roemmich and Gilson 2009) on a $1^{\circ} \times 1^{\circ}$ grid from $64.5^{\circ} \mathrm{S}$ to $64.5^{\circ} \mathrm{N}$ constructed from Argo temperature and salinity observations during 2006-13, after quality control and adjustment of pressure bias. To test how the mapping may affect the analysis in lightly sampled regions, we check that the resulting frontal locations are consistent with the original profile data (see the supplemental information).

\section{b. Methods to locate the fronts}

ACC fronts are associated with strong gradients in temperature and salinity and with deep-reaching jets (OWN95). Here, we compare two methods to identify the Subantarctic and Polar Fronts of the ACC in a gridded Argo product. The first approach locates fronts along DH contours that correspond to local maxima in vertically integrated shear [section $2 b(1)]$. The second approach follows the fronts along specific features in the potential temperature field [section $2 \mathrm{~b}(2)$ ], similarly to OWN95. Results (section 3) show the locations of the fronts as the probability of occurrence (Figs. 3, 4) and time averaged during 2006-13 (Figs. 2b, 5, 6, 10), once the annual variability is removed from the Argo fields (annual displacements of the fronts are not resolved by Argo). The DH and feature-based methods are in overall good agreement with each other, and only the DH approach is used in the second part of the manuscript.

\section{1) Fronts ALONG DYNAMiC HEIGHT CONTOUR LINES}

Fronts are characterized by strong geostrophic currents. To find those DH contours that are aligned with fronts, we consider a set of DH bins and count (for each) the number ( $N$; monthly) of collocated local maxima in 0-1975-dbar integrated shear (within the Argo domain 


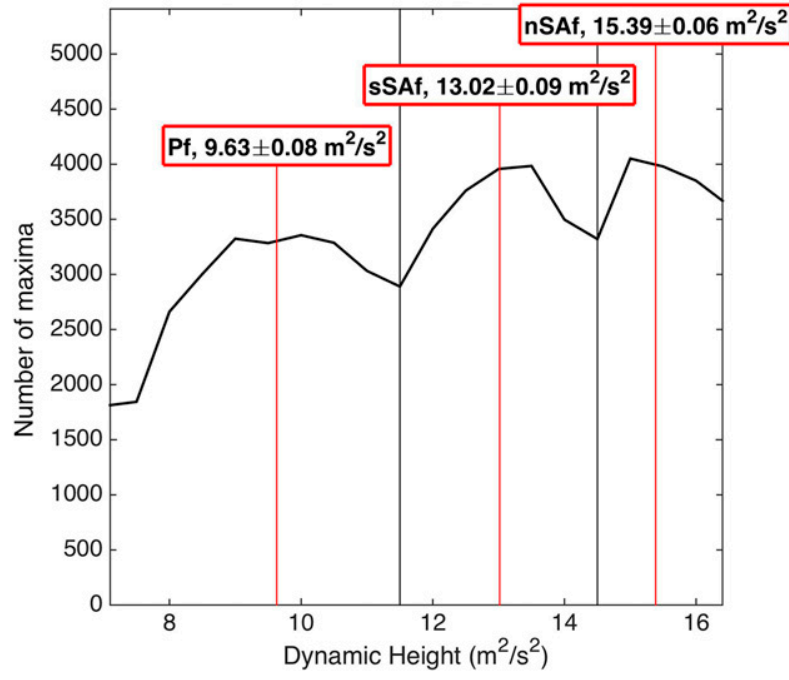

FIG. 1. Number of local maxima in vertically integrated geostrophic shear (0-1975 dbar) from gridded Argo data, considering all longitudes, latitudes (south of $35.5^{\circ} \mathrm{S}$ ), and months from 2006 to 2013, binned by DH. Gray lines separate DH ranges encompassing different fronts. Red lines indicate the DH contour assigned to each front (values and standard errors in red boxes, along with abbreviations for the fronts).

in the Southern Ocean), that is, local maxima in geostrophic velocity amplitude at the surface from $\mathrm{DH}$ referenced to $1975 \mathrm{dbar}$. The sum of $N$ (in time) is characterized by three peaks, each identifying a different DH range (Fig. 1). Each DH range is associated with a different front (e.g., front $i$ ), and a contour $\mathrm{DH}_{i}^{*}$ within that range is assigned to the front (red lines in Fig. 1). $\mathrm{DH}_{i}^{*}$ is the time-averaged $\mathrm{DH}$ of $\mathrm{DH}$ bins (within range $i$ ) that correspond to monthly local peaks in $N$. Thus, front $i$ is described using $\mathrm{DH}_{i}^{*}=\overline{\mathrm{DH}_{N_{\text {max }}}(t)}$, where $\mathrm{DH}_{N_{i_{\max }}}$ is associated with the maximum $N$ within the DH range $i$ (i.e., $N_{i_{\max }}$ ) for a given month $t$. The standard error of $\mathrm{DH}_{i}^{*}$ is related to the time variability of the $\mathrm{DH}$ bin that corresponds to $N_{i_{\max }}$ (i.e., $\mathrm{DH}_{N_{i_{\max }}}$ ) and is small (Fig. 1). Finally, the DH bin size in Fig. 1 is $0.5 \mathrm{~m}^{2} \mathrm{~s}^{-2}$. Varying this quantity between 0.15 and $0.7 \mathrm{~m}^{2} \mathrm{~s}^{-2}$ yields
$\mathrm{DH}^{*}$ values that are generally comparable to one another within error bars.

Based on their position and $\theta-S$ properties, the three fronts identified here are named, from north to south (i.e., decreasing values of DH contours): Northern Subantarctic Front (nSAf), Southern Subantarctic Front (sSAf), and Polar Front (Pf). These names do not necessarily correspond to those in other studies that describe a different number of cores for each ACC front (e.g., Sokolov and Rintoul 2002, 2007, 2009a; Anilkumar et al. 2006). The spatial scales of the gridded Argo product are larger than available altimetry products and cannot resolve all the cores of the ACC fronts. Also, Argo data still undersample the southern fronts of the ACC, where seasonal sea ice was once a hurdle for deployments (Klatt et al. 2007).

\section{2) FRONTS ALONG SPECIFIC FEATURES OF THE POTENTIAL TEMPERATURE FIELD}

Based on the description by OWN95 (their Table 3) and consistent with subduction and/or shoaling of water masses, we locate fronts in the Argo dataset along characteristic $\theta$ features (Table 1 ). That is, we locate a front at the intersection between a constant $\theta^{*}$ surface and (for the SAf) a pressure level or (for the Pf) a $\theta$ extremum surface (e.g., the maximum $\theta$ deeper than 800 dbar). We compare frontal locations by OWN95 with those estimated from Argo data using $\theta^{*}$ values consistent with OWN95 (see $\theta^{*}$ values in Table 1 and resulting frontal locations later in Fig. 5). OWN95 do not describe two branches of the Subantarctic Front but provide a $\theta$ range (at $400 \mathrm{dbar}$ ) to characterize it; we associate the minimum and maximum values of this $\theta$ range with the sSAf and nSAf, respectively. Also, we compute (Table 1) $\theta^{*}$ values along the frontal locations from the DH contour approach (i.e., the circumpolar and time average of $\theta$ at the $x-y$ intersection between the $\mathrm{DH}_{i}^{*}$ contour associated with front $i$ and the pressure level or $\theta$ extremum surface of interest) and compare the two (DH vs $\theta$ based) methods (Fig. 6). This procedure for local comparisons is motivated by the possibility of

TABLE 1. Time-mean $\theta^{*}\left({ }^{\circ} \mathrm{C}\right)$ from this study (i.e., along the DH-based ACC fronts from the gridded Argo data; Fig. 3), OWN95, and Sokolov and Rintoul (2009a, shortened to SR09 below; their Table 1). Values for both the middle and northern branch of the SAf in SR09 are in the nSAf column. The standard deviation $( \pm 1 \sigma)$ along the front is also indicated as well as water masses related to each criterion [Upper Circumpolar Deep Water (UCDW)]. Criteria that best match the DH method are in bold.

\begin{tabular}{|c|c|c|c|c|}
\hline & \multicolumn{2}{|r|}{ Pf } & sSAf & nSAf \\
\hline & $\operatorname{Min}(\theta)$ at $p \leq 200 \mathrm{dbar}$ & $\operatorname{Max}(\theta)$ at $p \geq 800$ dbar & \multicolumn{2}{|c|}{$\theta$ at $p=400 \mathrm{dbar}$} \\
\hline This study & $1.3 \pm 0.41$ & $2.17 \pm 0.06$ & $3.34 \pm 0.35$ & $5.05 \pm 0.63$ \\
\hline OWN95 & 2 & 2.2 & 4 & 5 \\
\hline \multirow[t]{2}{*}{ SR09 } & $1.15 \pm 0.16$ & $2.25 \pm 0.07$ & $2.78 \pm 0.15$ & $4.06 \pm 0.35,6.06 \pm 0.79$ \\
\hline & $\begin{array}{l}\text { Winter water dives } \\
\text { northward, } \theta_{\min }\end{array}$ & $\begin{array}{l}\text { UCDW shoals southward }\left(\theta_{\max }\right) \\
\text { or just } \theta \text { at } 800 \text { dbar }\end{array}$ & \multicolumn{2}{|c|}{ Colder ACC vs warmer subtropics } \\
\hline
\end{tabular}




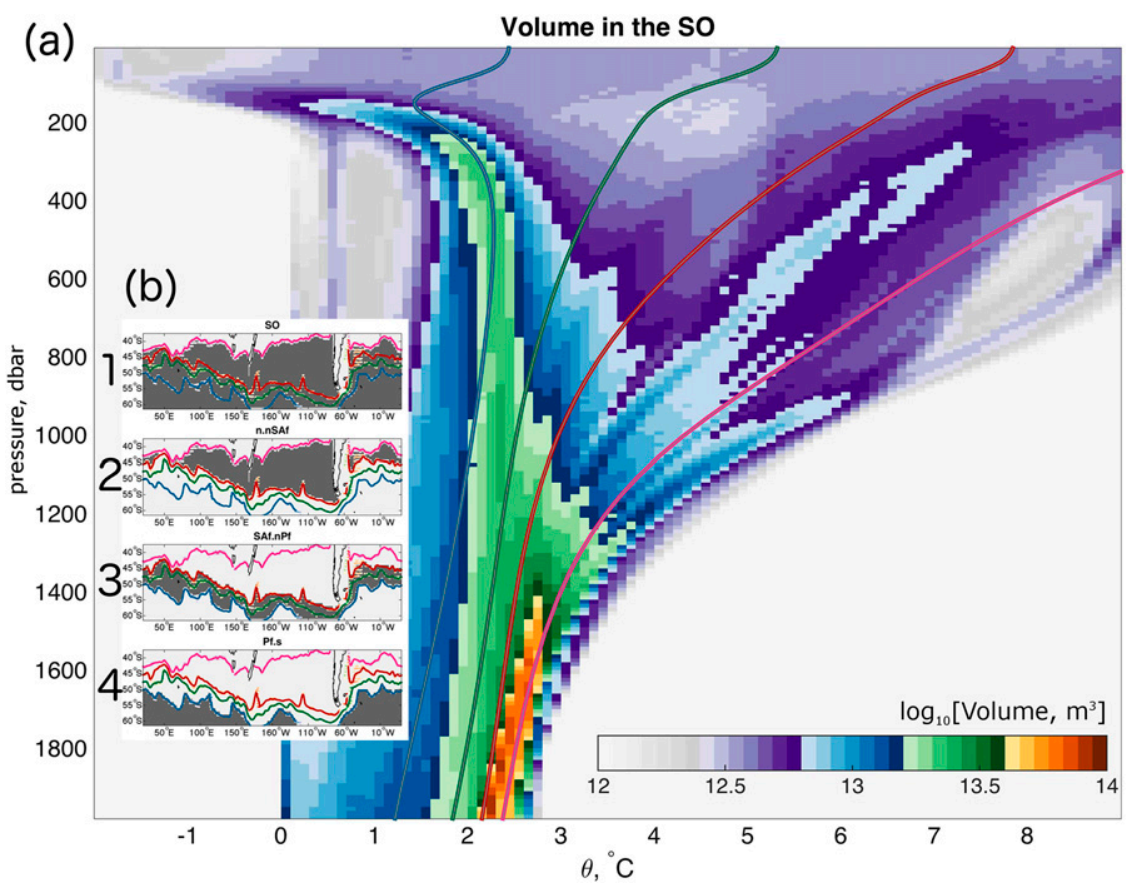

FIG. 2. (a) Time-mean volume in $\theta$ ( $x$ axis, ${ }^{\circ} \mathrm{C}$ ) and pressure ( $y$ axis, dbar) bins, within the Argo domain south of the STf, that is, gray shaded region in (b1). The volume in each bin $\left(\mathrm{m}^{3}\right)$ is equal to 10 power of the value shaded in color. The mean $\theta$ profiles along the DH-based Argo fronts in Fig. 3 (and along the STf) are indicated as thick lines (Pf in blue, sSAf in green, nSAf in red, and STf in magenta). (b) Regions of the Argo domain, considered in this study, are shaded gray: (b1) SO (south of the STf), (b2) n.nSAf (between the STf and the nSAf), (b3) SAf.nPf (nSAf to north of the Pf), and (b4) Pf.s (Pf and south). The time-mean locations of the Argo fronts are color coded as in panel (a).

using a $\theta$ contour as boundary between water masses (OWN95) and by an overall circumpolar agreement between the $\mathrm{DH}$ - versus $\theta$-based (i.e., water mass based) approaches. Such agreement is seen in how the average $\theta$ profiles along the DH-based Pf, sSAf, and nSAf separate regions where the water mass volumes in the Southern Ocean (within the Argo domain) peak (Fig. 2a), that is, where $\theta$ values are fairly homogeneous and characteristic of that region and pressure level (regions at the boundary of the domain are not well represented in Fig. 2a). These peaks, although sometimes weak (e.g., between the sSAf and the nSAf), have a coherent structure in the $p-\theta_{\text {bin }}$ plane, consistent with a circumpolar frontal structure of the ACC that can be described using $\theta$ criteria (OWN95). Yet the peaks are not observed at all individual longitudes, partially due to the resolution of the data (especially where different fronts are close to one another) and the limited southward extent of the Argo domain.

We evaluate a set of $\theta$ features or criteria for each front (see Table 1 and supplemental material; in this manuscript, the word "criteria" is used in the context of the $\theta$ method to locate the fronts, which is based on, but does not strictly follow, the characterization in OWN95). Here, we focus on those criteria that align best with results from the DH contour method, that is, yield the best overall agreement both in circumpolar location, and $\theta-S$ properties at different pressure levels. These criteria (Table 1 , in bold) include $\theta^{*}$ values of the maximum $\theta[\max (\theta)]$ deeper than $800 \mathrm{dbar}$ (to locate the Pf) and of $\theta$ at $400 \mathrm{dbar}$ (to locate the sSAf and the nSAf). For the Pf, the $\max (\theta)$ criterion at $p \geq 800$ dbar does not strictly follow the characterization in OWN95. OWN95 describe the Polar Front as being south of where $\theta_{\max }>2.2^{\circ} \mathrm{C}$ at $p \geq 800$ dbar (their Table 3 ), with $\theta_{\max }$ as a local vertical maximum. In the Argo dataset, this $\theta_{\max }$ is generally shallower than 800-850 dbar (not shown); hence, the max $(\theta)$ at the $p \geq 800 \mathrm{dbar}$ criterion (Table 1) captures $\theta_{\max }$ only at some longitudes and constrains $\theta$ at $800 \mathrm{dbar}$ elsewhere [since $\max (\theta)$ is the largest value of $\theta$ in a pressure range and not necessarily a local vertical maximum].

The $\theta_{\max }$ at depth is related to a $\theta_{\min }$ (i.e., $\theta$ local vertical minimum) in the upper ocean, which has been used to characterize the Polar Front (OWN95) and is described here as an alternate $\theta$ criterion, although it 
does not align with the DH-based Pf as well as an isotherm along the $\max (\theta)$ at $p \geq 800$ dbar does. This $\theta_{\min }$ is present only during summer. Hence, with year-round data from Argo, we favor the deeper criteria in this analysis. Also, the $\theta_{\min }$ is generally shallower than $200 \mathrm{dbar}$ (not shown); hence, the minimum $\theta[\min (\theta)]$ at the $p \leq 200$ dbar criterion we use (Table 1 ) is equivalent to the characterization in OWN95 (their Table 3), except that it includes profiles where the $\theta_{\min }$ is not present (e.g., wintertime profiles; common in Argo data but not previous hydrographic data). We discuss other $\theta$ and $S$ features along the fronts and how they align with the DH-based approach in the supplemental material.

\section{c. Freshwater estimate from Argo salinity anomaly}

Freshwater (FW) anomalies for a region of interest are estimated as centimeters of freshwater over the area of the Southern Ocean in the gridded Argo domain $\left(A_{\mathrm{SO}}=6.001 \times 10^{13} \mathrm{~m}^{2}\right)$, that is, $\mathrm{FW}=V_{\mathrm{FW}} / A_{\mathrm{SO}}$. The freshwater volume $V_{\mathrm{FW}}$ is defined as the amount of freshwater that would need to be added to or removed from a reference volume $V_{m}$ (with salinity $S_{m}$ ) in order to obtain salinity $S_{i}$ (at time step $i$ ), without modifying the salt content of the water, that is, $V_{\mathrm{FW}}=\int\left[\left(S_{m} / S_{i}\right)-1\right] d V_{m}$. Here, $V_{m}$ is the volume associated with the Argo grid in the region and pressure levels of interest, and $S_{m}$ and $S_{i}$ are the corresponding time mean and time-changing salinity.

\section{The Polar and Subantarctic Fronts of the ACC from Argo}

\section{a. Fronts along dynamic height contour lines}

The location of the Pf cannot be determined everywhere in the Pacific sector of the Southern Ocean, since, at some longitudes, the $\mathrm{Pf}$ is poleward of the Argo domain and the gridded maps. The Argo Pf shows good agreement with (i.e., only slight differences from) OWN95's estimate in Drake Passage (Fig. 3, red 1) between the Maurice Ewing Bank (Fig. 3, red 2) and the Atlantic Ridge (Fig. 3, red 4), between $150^{\circ}-170^{\circ} \mathrm{E}$ and $175^{\circ}-120^{\circ} \mathrm{W}$ in the Pacific, and between $35^{\circ}-55^{\circ} \mathrm{E}$ and $100^{\circ}-115^{\circ} \mathrm{E}$ in the Indian sector (Fig. 3). In other regions, the Argo Pf is farther south than the previous estimate of OWN95 and is more consistent with the midbranch of the Polar Front in Sokolov and Rintoul (2009a), which generally agrees well with our Argo Pf circumpolar location. We observe a large southward shift in the Argo Pf position relative to OWN95 at the Maurice Ewing Bank [Fig. 3, red 2; consistent with Sokolov and Rintoul (2009a) and Kim and Orsi (2014)], in the eastern Atlantic and between $115^{\circ}$ and $145^{\circ} \mathrm{E}$ [consistent with Sokolov and Rintoul (2009a) and different from Kim and Orsi (2014)], and around the Kerguelen Plateau (Fig. 3, red 6), with the Argo Pf flowing just north of the Fawn Trough (Fig. 3, red 7). In this region, our results are consistent with Sparrow et al. (1996) and Sokolov and Rintoul (2009a) but neither Kim and Orsi (2014) nor Park et al. (2014) (discussed further in section 3b).

We find two cores of the Subantarctic Front in the Argo dataset: the sSAf and the nSAf. Along most of their circumpolar path, these two cores are consistent with the southern and midbranch of the Subantarctic Front in Sokolov and Rintoul (2009a), respectively, with the largest differences in the Pacific Ocean, east of the Campbell Plateau (Fig. 3, red 9). Here, the nSAf sharply veers northward to follow the bathymetry and comes back to the south around $180^{\circ}$, consistent with the Subantarctic Front in Böning et al. (2008) and Kim and Orsi (2014) and with the northern (rather than the middle) branch of the Subantarctic Front in Sokolov and Rintoul (2009a). Similarly, the nSAf sharply veers northward at the East Pacific Rise (Fig. 3, red 14), again in agreement with Böning et al. (2008) and the northern (rather than the middle) branch of the Subantarctic Front in Sokolov and Rintoul (2009a) but not with Kim and Orsi (2014), where no sharp northward meandering is observed. In general, the Argo sSAf traces more closely (than the nSAf) the location of the Subantarctic Front in OWN95, except in the western Atlantic (near South America), in the Indian Ocean eastward of $70^{\circ} \mathrm{E}$, and in the eastern Pacific. Also, in OWN95, both the Subantarctic and Polar Fronts cross the Pacific-Antarctic Ridge via the Udintsev Fracture Zone (Fig. 3, red 11). Results here suggest that only the Pf does (Fig. 3, red 11), in agreement with Kim and Orsi (2014) and Sokolov and Rintoul (2009a), while the sSAf goes through the Eltanin Fracture Zone (Fig. 3, red 12) and the nSAf goes through the Menard Fracture Zone (Fig. 3, red 13). However, the Argo climatology resolution may be a limitation when describing the front position in relation to these narrow bathymetric features.

The location of the ACC fronts from Argo agrees well with local maxima of the zonal and meridional baroclinic geostrophic transport in the upper 1975 dbar from Argo (Fig. 4, with velocities referenced to 1975 dbar). Such agreement is expected on the overall circumpolar scale [since $\mathrm{DH}_{i}^{*}$ contour values are chosen based on Argo integrated shear on a circumpolar scale; section 2b(1)], and Fig. 4 shows that it also holds locally. As an example, the northward meandering of the nSAf east of the Campbell Plateau (Fig. 3, red 9) and at the East Pacific Rise (Fig. 3, red 14) aligns with a pattern of stronger meridional velocities (Fig. 4b). The strongest integrated transport is in the western Indian Ocean, associated with the Agulhas retroflection (Fig. 4a). 


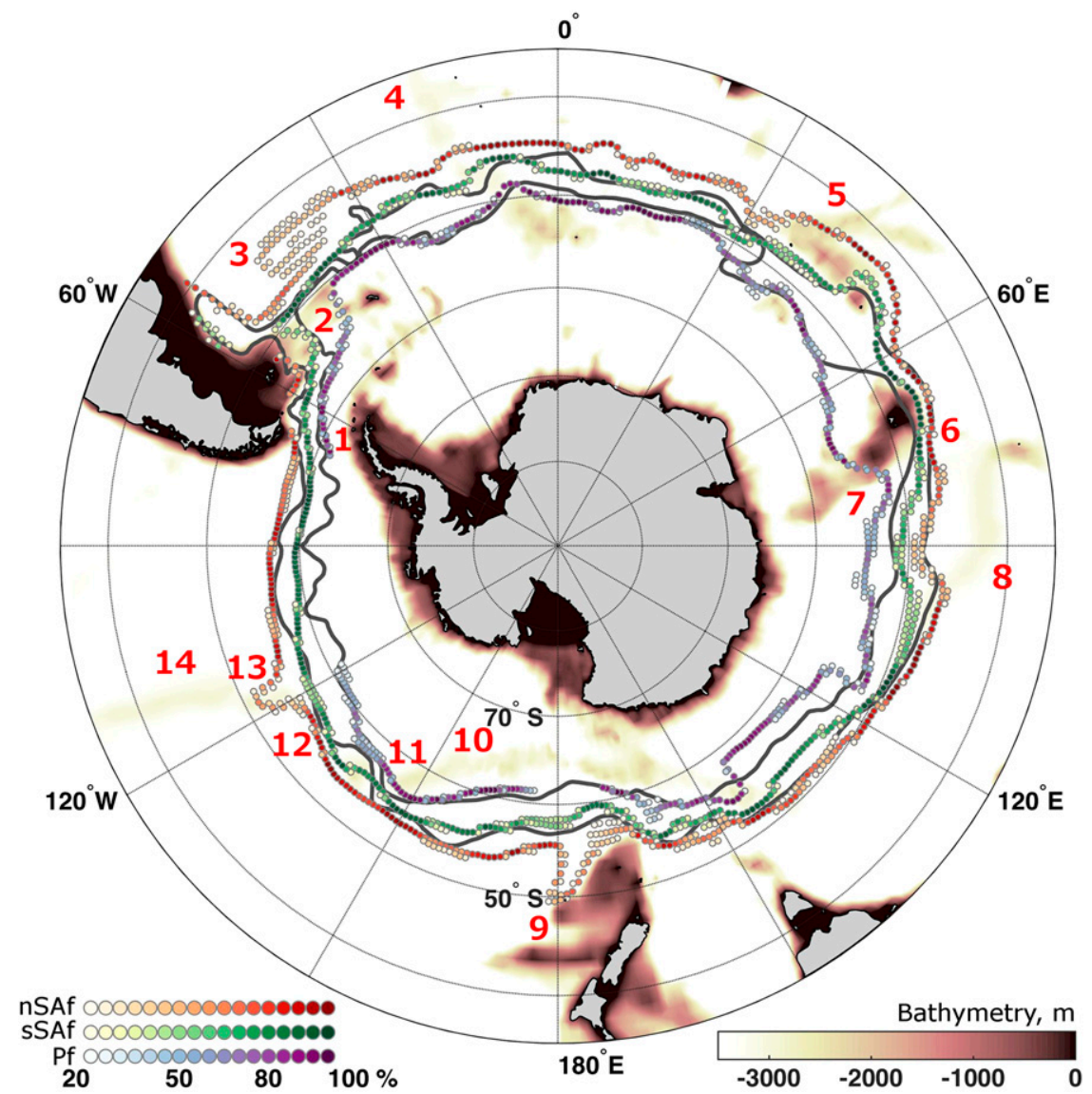

FIG. 3. DH-based ACC fronts from gridded Argo data: frequency of occurrence (dots) during 2006-2013 (values smaller than 20\% are masked out). Light blue to purple dots are for the Pf. Light yellow to green dots are for the sSAf. Light orange to red dots are for the nSAf. Black lines are, from north to south, the Subantarctic and Polar Fronts described in OWN95. Bathymetry $(\mathrm{m})$ shallower than $3500 \mathrm{~m}$ is shaded from white to dark brown in the background. Numbers (red) are adjacent to some of the main bathymetric features: 1) Drake Passage, 2) Maurice Ewing Bank, 3) Argentine basin, 4) Atlantic Ridge, 5) Southwest Indian Ridge, 6) Kerguelen Plateau, 7) Fawn Trough, 8) Southeast Indian Ridge, 9) Campbell Plateau, 10) Pacific-Antarctic Ridge, 11) Udintsev Fracture Zone, 12) Eltanin Fracture Zone, 13) Menard Fracture Zone, and 14) East Pacific Rise.

\section{b. Fronts along specific features of the potential temperature field}

The Pf location using $\theta^{*}$ values by OWN95 in the Argo $\theta$ field [section $2 \mathrm{~b}(2)]$ is in overall agreement with OWN95, but regional discrepancies between the shallower and deeper criterion are large between $50^{\circ}$ and $80^{\circ} \mathrm{E}, \sim 115^{\circ}$ and $140^{\circ} \mathrm{E}$, and $\sim 170^{\circ}$ and $150^{\circ} \mathrm{W}$ (Fig. 5). Around the Kerguelen Plateau (i.e., $50^{\circ}-80^{\circ} \mathrm{E}$ ), a Pf criterion on the $\max (\theta)$ deeper than 800 dbar yields a path of the Pf that is south compared to the upper-ocean $\min (\theta)$ criterion (Fig. 5), except for some of the individual Argo profiles that align with the shallower criterion between $70^{\circ}$ and $80^{\circ} \mathrm{E}$ (Fig. S1c in the supplemental information). These profiles do not fall on a circumpolar path (Fig. S1c), and the corresponding $\theta$ field yields large error bars for the Pf from the $\max (\theta)$ criterion in Fig. 5 (between $70^{\circ}$ and $80^{\circ} \mathrm{E}$ ). In summary, the shallower criterion suggests a Pf location (in the region of interest) that is to the north compared to following $\theta^{*}$ along max $(\theta)$ deeper than 800 dbar. The shallower criterion is based on a $\theta_{\min }$ (OWN95) that is present only during summer. With year-round data from Argo, we favor the deeper criteria in this analysis.

Using $2^{\circ} \mathrm{C}$ as the $\theta^{*}$ value for the $\min (\theta)$-based $\mathrm{Pf}$ (as in Fig. 5) is consistent with Table 3 in OWN95 and is similar to the criterion in Park et al. (2014) (who consider $\theta_{\min }$ in the $100-300-m$ depth range), but the resulting front location is different from both of the other studies. In the gridded Argo product used here, the $2^{\circ} \mathrm{C}$ 


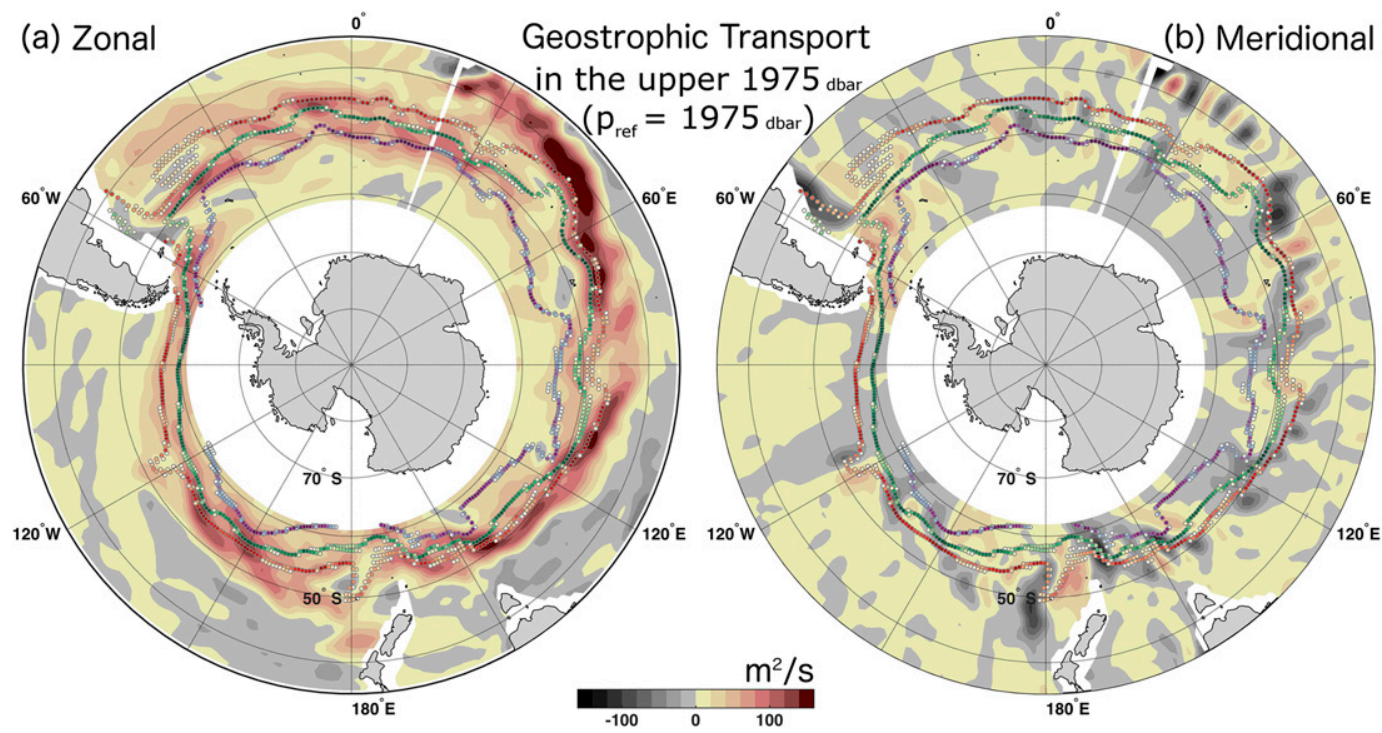

FIG. 4. DH-based Argo fronts as in Fig. 3, with the background color showing the time-mean (a) zonal and (b) meridional baroclinic geostrophic transport per unit meter $\left(\mathrm{m}^{2} \mathrm{~s}^{-1}\right)$, in the upper $1975 \mathrm{dbar}$ from gridded Argo data.

contour of the minimum $\theta$ in the upper 200 dbar [i.e., a $\min (\theta)$-based $\mathrm{Pf}]$ sharply veers northward at the plateau $\left(65^{\circ}\right.$ E; Fig. 5), while in OWN95 their Polar Front gently veers northward between $55^{\circ}$ and $\sim 62.5^{\circ} \mathrm{E}$ (Fig. 5), and in Park et al. (2014), the $2^{\circ} \mathrm{C}$ isotherm that corresponds to their Polar Front veers northward around $71^{\circ} \mathrm{E}$ (their Fig. 5). A northward change in direction, west of $70^{\circ} \mathrm{E}$, as in the gridded Argo product here, is consistent with individual Argo profile observations (see the supplemental information).

The sSAf and the nSAf locations using $\theta^{*}$ values by OWN95 in the Argo $\theta$ field [section 2b(2)] align with the Subantarctic Front in OWN95 only in a few sectors of the ACC (e.g., around $110^{\circ} \mathrm{E}$; Fig. 5). At other longitudes, one of them may be close to the previous estimate but not the other (e.g., the sSAf around $175^{\circ} \mathrm{W}$ ) or they are both far (generally to the north, e.g., in the Atlantic basin). Sectors of the Southern Ocean where Argo fronts based on $\theta^{*}$ values in OWN95 are equatorward of the position in OWN95 indicate that the regional Argo climatology at the pressure levels of interest (for the criteria) is colder than previous observations (collected between 1976 and 1990 for sections in the Atlantic Ocean and 1974-77 in the western Indian basin). Unfortunately, a regional long-term trend cannot be estimated due to the sparsity of observations in the Southern Ocean for the period previous to Argo. The simple comparison (here) of the Argo versus OWN95

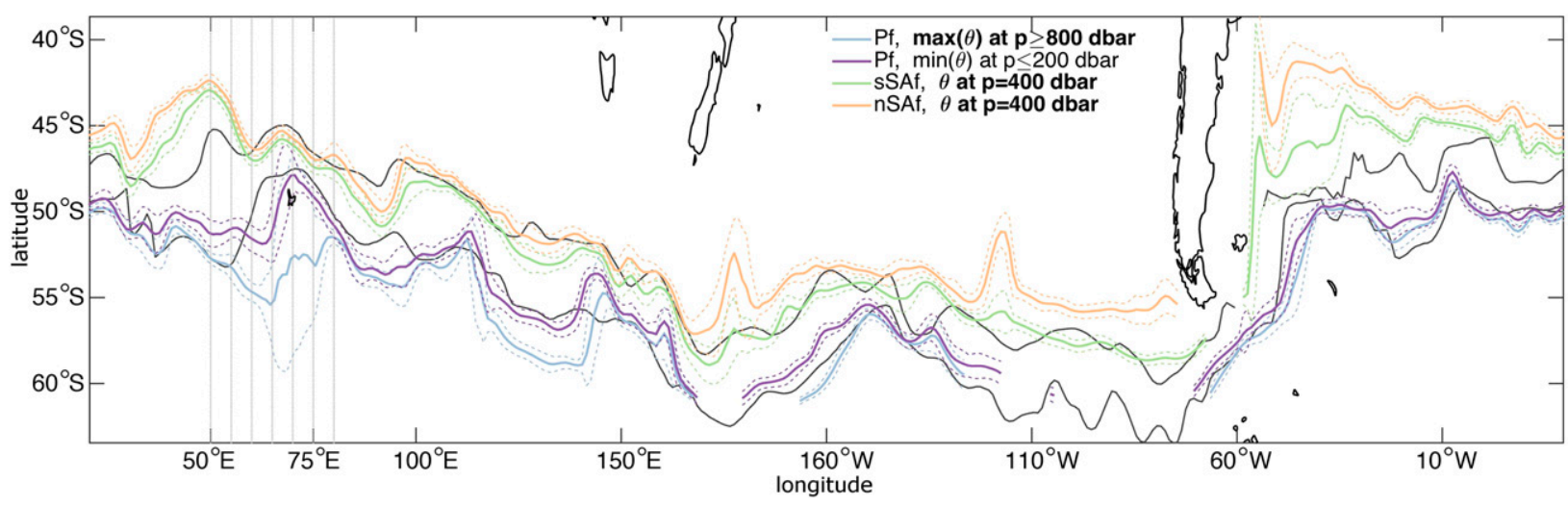

FIG. 5. Argo fronts from $\theta$ criteria (thick lines), using $\theta^{*}$ values consistent with OWN95 (Table 1): $x, y$ locations are averaged in $1^{\circ}$ longitude bins and in time. Error bars (dashed lines) include a component related to the bin average and another equal to one (temporal) standard deviation of the front meridional location. Bold fonts highlight, in the legend, $\theta$ criteria that align best with DH-based fronts. Polar and Subantarctic Fronts from OWN95 are shown as black lines. A $5^{\circ}$ grid is added along the $x$ axis between $50^{\circ}$ and $80^{\circ} \mathrm{E}$. 


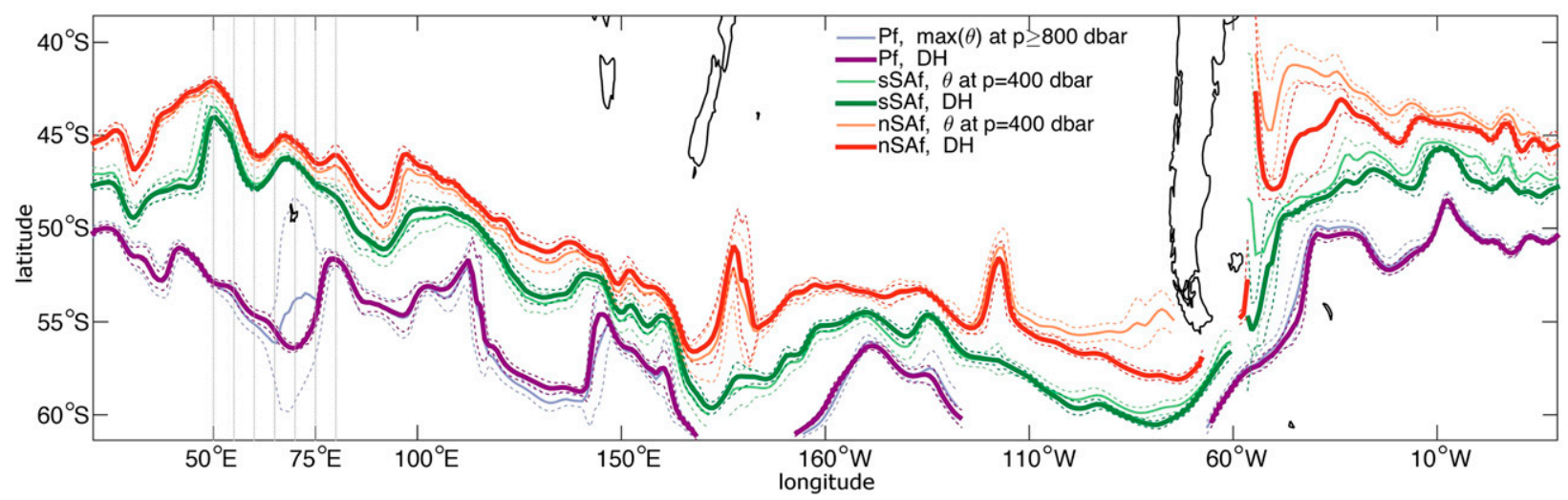

FIG. 6. DH- (thick lines) and $\theta$-based (thin lines) Argo fronts (with $\theta^{*}$ values computed along the DH-based fronts; Table 1 ): $x, y$ locations are averaged in $1^{\circ}$ longitude bins and in time. Error bars (dashed lines) include a component related to the bin average and another equal to one (temporal) standard deviation of the front meridional location. A $5^{\circ}$ grid is added along the $x$ axis between $50^{\circ}$ and $80^{\circ} \mathrm{E}$.

frontal locations may be aliased by interannual and decadal variability as well as by differences between the two datasets (temporally and spatially distributed Argo profiles vs synoptic, mostly summertime sections) and methods. Yet Argo profile data (with no annual cycle removed; Fig. S1b) that follow the $2^{\circ} \mathrm{C}$ shallow criterion lay north of the Polar Front location in OWN95 in the same ACC sectors $\left(140^{\circ}\right.$ $170^{\circ} \mathrm{E}$ and $175^{\circ} \mathrm{E}-120^{\circ} \mathrm{W}$ ) as for the gridded data (with the annual cycle removed; Fig. 5). Also, ECMWF ERAInterim sea surface temperature (SST) shows a statistically significant linear decrease between 1979 and 2013 in the general ACC Pf region at those longitudes (not shown), consistent with a local long-term cooling of the upper ocean and with the $\min (\theta)$-based Argo Pf being equatorward of the Polar Front in OWN95. Regional cooling is not inconsistent with the overall warming of the Southern Ocean observed for the last few decades and during the Argo period (Roemmich et al. 2015).

We compute $\theta^{*}$ values (analogous to those of OWN95) along DH contours that identify fronts as in section $2 b(1)$ (Table 1). Resulting frontal locations are in overall good agreement with the DH contour approach (Fig. 6), showing how the two methods, described in section $2 b(1)$ and $2 b(2)$, align regionally [the agreement on a circumpolar scale is discussed in section $2 \mathrm{~b}(2)]$.

Also, the $\theta^{*}$ value of the upper-ocean $\min (\theta)$ computed along the DH-based Argo Pf agrees, within error bars, with the value in Sokolov and Rintoul (2009a) but not OWN95 (Table 1). However, the value of the max $(\theta)$ at $p \geq 800$ dbar along the DH-based Argo Pf agrees with both the previous findings, as does $\theta(400 \mathrm{dbar})$ along the DH-based Argo nSAf (Table 1). In contrast, along the DH-based Argo sSAf, $\theta(400$ dbar $)$ differs from both OWN95 and Sokolov and Rintoul (2009a; Table 1). A main advantage in computing $\theta^{*}$ values along DH-based (i.e., streamline based) fronts here resides in having both the streamfunction and the $\theta$ field from the same well-resolved (Argo) dataset and for the same time period (2006-13).

Argo fronts from $\theta$ criteria that generally agree best with the DH contour method (in bold in Table 1, with $\theta^{*}$ values computed along DH-based fronts) still fail to align with it in a few regions (Fig. 6), suggesting that, in specific sectors of the Southern Ocean, a combination of different criteria (Table 1 and supplemental material) may be appropriate to locate the fronts more accurately when using a feature-based approach. In the eastern Pacific, the nSAf (from $\theta$ ) hits the South American coast, rather than flowing through Drake Passage. This may be related to how formation of Subantarctic Mode Water (SAMW) impacts the $\theta$ field in the region and can be corrected using a regional criterion on $\theta$ at $600 \mathrm{dbar}$ (see the supplemental information). Around $90^{\circ} \mathrm{E}$, the $\theta$-based sSAf and nSAf flow south of the corresponding DH fronts (a 600-dbar criterion for $\theta$ would reduce this departure too). In the Atlantic basin, the sSAf and nSAf flow north of the DH fronts (reduced applying a salinity criterion in the region).

\section{c. $\theta-S$ properties along the fronts: Time mean and interannual variability}

Time-mean $\theta-S$ diagrams along the Pf and the nSAf are similar using the DH contour method versus $\theta$ criteria with $\theta^{*}$ values by OWN95 (Fig. 7a). However, the sSAf from the latter shows $\theta-S$ properties in between the DH-based sSAf and nSAf (Fig. 7a).

The Pf $\theta$-S diagram from Argo shows a $\theta$ minimum $\left(\theta_{\min }\right)$ in the upper $200 \mathrm{dbar}$ and a $\theta$ maximum $\left(\theta_{\max }\right)$ at depth (Fig. 7b), as described in OWN95. However, the $\theta_{\min }$ is colder than $2^{\circ} \mathrm{C}$, and the $\theta_{\text {max }}$ is between 400 and $700 \mathrm{dbar}$, consistent with the description in section $3 \mathrm{~b}$.

The $\theta^{*}$ values computed along the $\mathrm{DH}$ frontal locations yield fronts with $\theta-S$ properties that agree well 
(a)

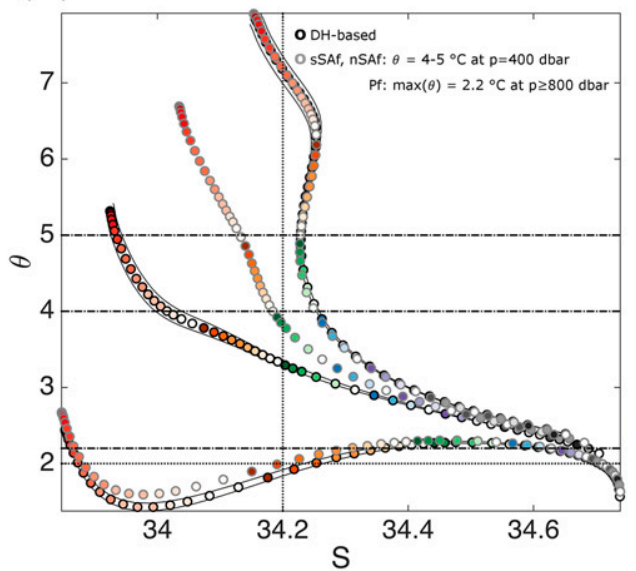

(b)

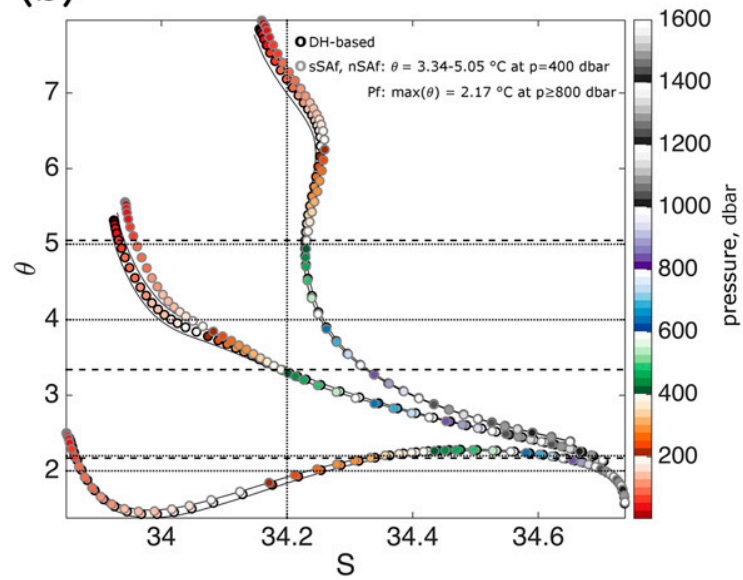

FIG. 7. Comparison of time-mean $\theta-S$ diagrams along the DH-based Argo fronts in Fig. 3 (black-edged dots in both panels), with (a) those from the $\theta$-based Argo fronts (in bold) in Fig. 5 [gray-edged dots in panel (a)], and (b) those in Fig 6 [gray-edged dots in panel (b)]. Values of $\theta$ proceed from colder to warmer along the Pf, sSAf, and nSAf. Error bars (black solid lines) are indicated for the DH-based fronts, consistent with the error on the DH contour choice associated with each front (Fig. 1). In both panels, dotted lines indicate $\theta^{*}-S^{*}$ values described in OWN95. Dashed lines indicate $\theta^{*}$ values used to locate the $\theta$-based fronts [different between (a) and (b)]. In (a), dashed lines coincide with dotted ones, since $\theta^{*}$ values are from OWN95. In (b), dashed lines are for $\theta^{*}$ computed along DH-based fronts. Dot colors represent mean pressure (dbar) at the $\theta-S$ values along the fronts.

with the DH method (Fig. 7b). While this result is expected at the pressure level of interest for the $\theta$ criteria (since $\theta^{*}$ values are computed along DH fronts), the overall agreement of the $\theta-S$ curves is further evidence of how the two methods, described in sections $2 b(1)$ and $2 \mathrm{~b}(2)$, are consistent with appropriate $\theta^{*}$ choices. Also, the difference in salinity arising from using one approach versus the other for the SAf is consistent with the observed northward departures of the $\theta$-based sSAf and nSAf in the Atlantic compared to the $\mathrm{DH}$ approach (Fig. 6) and could be reduced by including a regional salinity criterion. Results in the rest of the manuscript are based on the DH contour method.

$\theta-S$ properties of the Argo nSAf and Pf show interannual variability during 2006-13 (Fig. 8). Deeper than 200 dbar, the nSAf was warmer and saltier in 2008 compared to 2011 (Fig. 8a), while the Pf was colder and fresher in 2006-09 compared to 2011-13 (Fig. 8b). At these pressure levels, changes in $\theta$ and $S$ are mostly compensating in density. This is not the case for the Pf $\theta_{\min }$ in the upper $200 \mathrm{dbar}$, where $\theta-S$ properties were colder and saltier in 2006/07 compared to 2010/11 (Fig. 8b). Since the $\theta-S$ properties of interest are along a fixed DH contour, $\theta-S$ anomalies must compensate in density in a vertically integrated sense.

\section{Heat and freshwater content in the Southern Ocean}

We describe changes in heat and freshwater content in different regions around the ACC. We define these regions (within the Argo domain) based on the timemean location of the Polar Front, Subantarctic Front, and Subtropical Front (STf; section 3a; Fig. 2b). The SO region extends south of the STf, n.nSAf is between the STf and the nSAf, SAf.nPf extends from the nSAf to the north of the Pf, and Pf.s includes the Pf and south of it. The STf is used as our northernmost boundary and is located along the $12^{\circ} \mathrm{C}$ isotherm at $100 \mathrm{dbar}$ (OWN95). Because of the time-constant boundary for each region, frontal shifts may influence $\theta-S$ changes locally within the region, yet the effect on resulting circumpolar heat and freshwater anomalies may be small [e.g., meridional displacements may be to the south at some longitudes and to the north at others (Shao et al. 2015)]. Also, interannual variability in frontal locations may not be large enough to be detected robustly in Argo.

We describe interannual variability of heat and freshwater content in pressure ranges and density classes (water masses) in section $4 \mathrm{a}$ and related $\theta-S$ anomalies in section $4 \mathrm{~b}$. In section $4 \mathrm{c}$, we discuss how wind-forced vertical advection (i.e., Ekman downwelling) causes isopycnals to deepen in 2010-12, contributing to the observed ocean warming signal.

\section{a. Heat and freshwater content interannual variability}

The SO heat content (in the upper $1975 \mathrm{dbar}$ ) increased during 2006-13 (Roemmich et al. 2015; Fig. 9a) with contributions from all three of the regions considered here and especially n.nSAf (red line, Fig. 9a). Most 
(a)

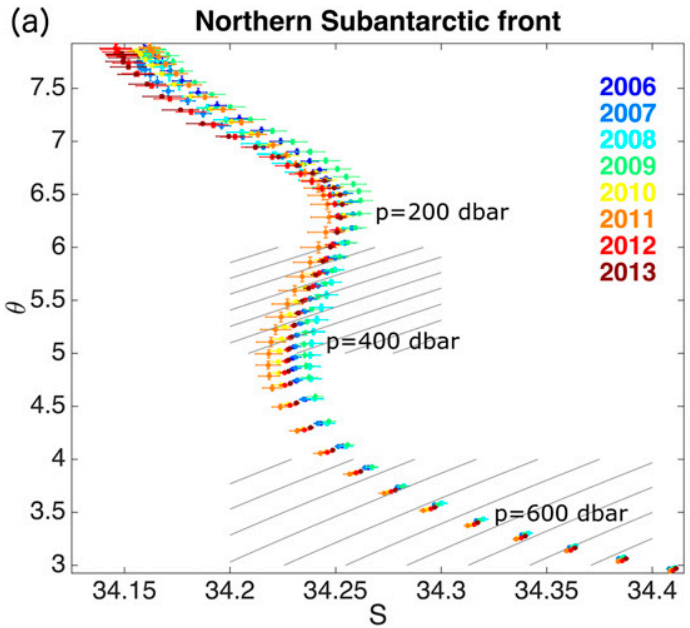

(b)

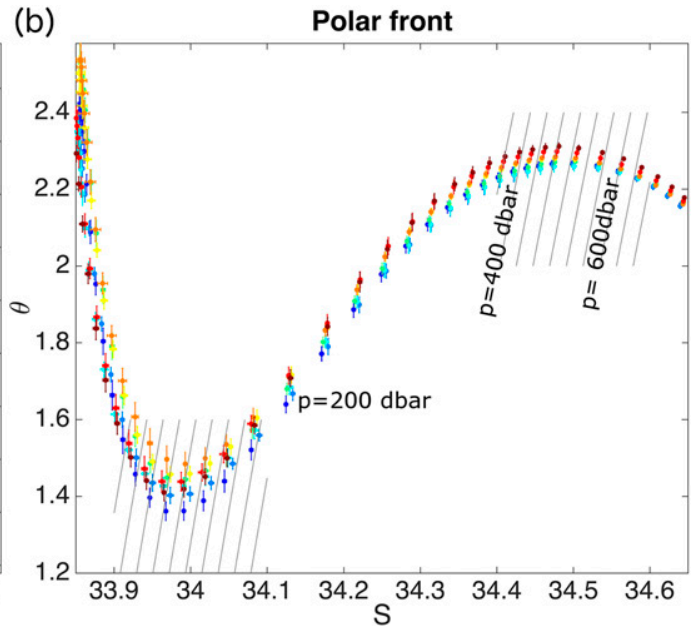

FIG. 8. Yearly $\theta-S$ diagrams along the Argo (a) nSAf and (b) Pf in Fig. 3. Error bars are shown around each dot. Gray contours indicate isopycnals. The 200-, 400-, 600-dbar pressure levels are marked, with pressure increasing from warmer to colder for the nSAf and from fresher to saltier for the Pf.

of this increase is confined to the top 1000 dbar (Figs. $9 \mathrm{c}, \mathrm{e})$, with a weaker signal between 1000 and $1500 \mathrm{dbar}$ (Fig. 9g) and a positive anomaly in 2006 for the Pf.s region between 1500 and 1975 dbar (Fig. 9i, blue line). At these pressure levels the SO anomaly in 2006 and 2007 is smaller than the related standard error, while the n.nSAf heat content is characterized by negative anomalies in 2006-09 and positive later, as in shallower layers.

The SO freshwater anomaly in the upper $1975 \mathrm{dbar}$ (computed as in section 2c) is negative in 2009 and 2013 and positive in 2011/12, with different contributions from different regions (Fig. 9b). In n.nSAf, the FW anomaly is positive in 2006/07 and 2011 and negative in $2012 / 13$, as a nearly linear decrease that dominates the SO signal in the upper $500 \mathrm{dbar}$ (Fig. 9d, red line) is added to increasing freshwater between 1000 and 1975 dbar (Figs. 9h,j), with the transition occurring between 500 and 1000 dbar (Fig. 9f). The SAf.nPf region too has different phasing between the upper $500 \mathrm{dbar}$ and the deeper levels, with a contribution to the SO signal that is small in the shallowest layer and larger at depth. Finally, Pf.s provides the smallest contribution to the FW interannual variability in the SO, with the exception of the 2011 positive and 2013 negative anomalies (Fig. 9b, blue line) that are related to changes in shallower (Fig. 9d) and deeper (Figs. 9f,h,j) layers, respectively. The yearly freshwater anomaly (in the upper 1975 dbar; Fig. 9b) varies spatially in each region (Fig. 10). The 2006/07 positive anomaly (Fig. 9b) is dominated by variability in the Indian sector of n.nSAf, south of the nSAf in the central South Pacific and south of the STf in the South Atlantic (especially in 2007) (Figs. 10a,b). However, the 2011/12 positive anomaly (Fig. 9b) is set by variability south of the nSAf in the south Indian Ocean, in n.nSAf and SAf.nPf in the central and eastern South Pacific and western (and eastern, in 2012) South Atlantic, and in the Pf.s region (in 2011) (Figs. 10f,g). The 2009 negative anomaly (Fig. 9b) is dominated by the signal south of the nSAf in the south Indian Ocean, south of the STf in the central and eastern South Pacific and western South Atlantic, and in n.nSAf and SAf.nPf in the eastern South Atlantic (Fig. 10d). Finally, the 2013 negative anomaly (Fig. 9b) is set by the signal in the Indian sector of n.nSAf, south of the STf in the western and central South Pacific, and south of the Pf in the central and eastern Atlantic and in the western Indian Ocean (Fig. 10h).

Overall warming during 2006-13 is also observed for water masses in the potential density $\sigma_{\theta}$ range $26.8 \leq \sigma_{\theta} \leq 27.7 \mathrm{~kg} \mathrm{~m}^{-3}$ (Fig. 11, top panels), with a stronger signal for SAMW $\left(26.8 \leq \sigma_{\theta} \leq 27.0 \mathrm{~kg} \mathrm{~m}^{-3}\right)$. FW anomalies indicate freshening of water masses for $27.0 \leq \sigma_{\theta} \leq 27.45 \mathrm{~kg} \mathrm{~m}^{-3}$ (Fig. 11e), with positive anomalies also in $2006 / 07$ for $\sigma_{\theta}>27.45 \mathrm{~kg} \mathrm{~m}^{-3}$. Also, the n.nSAf contribution to the SO signal for $\sigma_{\theta}>27.0 \mathrm{~kg} \mathrm{~m}^{-3}$ is a FW increase during the Argo years, at all levels. In contrast, in the SAf.nPf and Pf.s regions, for $\sigma_{\theta}>27.35 \mathrm{~kg} \mathrm{~m}^{-3}$, water masses are characterized by a positive FW anomaly in 2006, 2007 (for SAf.nPf), and 2011-12 (Figs. 11g,h).

Finally, the FW anomaly in the SAMW range $26.8 \leq$ $\sigma_{\theta} \leq 26.9 \mathrm{~kg} \mathrm{~m}^{-3}$ is negative at the end of the time series and positive before that (Figs. 11e,f).

\section{b. $\theta-S$ property changes on isopycnals}

Heat and freshwater changes in potential density classes described here (Fig. 11) are based on mean 
(a) $\times 10^{21}$ Heat (J), p = 0-1975 dbar

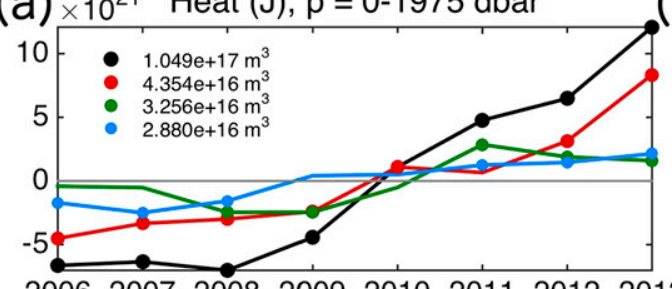

20062007200820092010201120122013

(C)

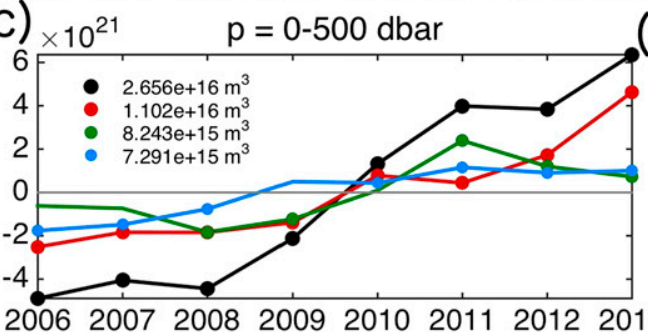

(b) Freshwater (cm on SO), $p=0-1975 \mathrm{dbar}$

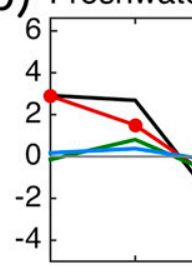

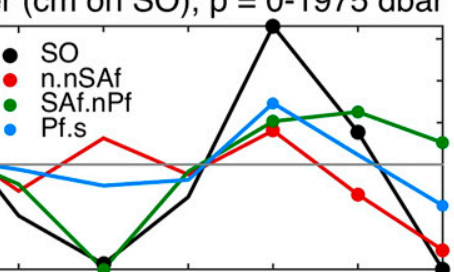

d) $\quad p=0-500 \mathrm{dbar}$

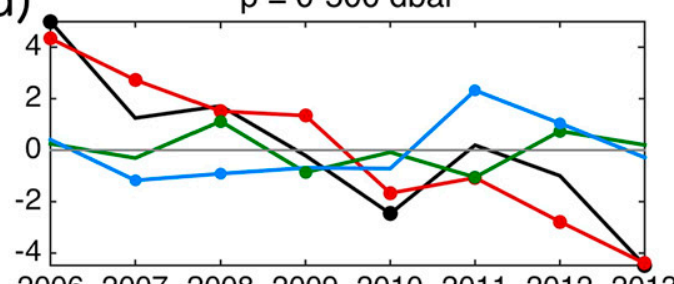

(e) $\times 10^{21} \quad \mathrm{p}=500-1000 \mathrm{dbar}$

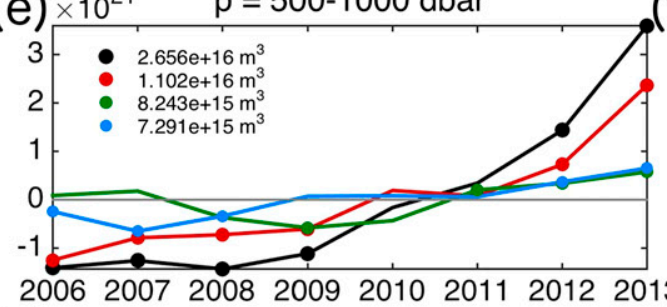

(f)

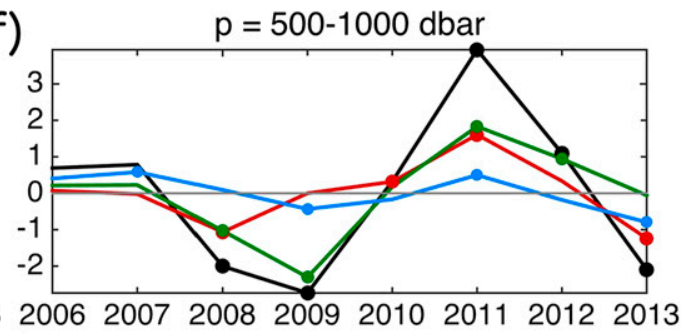

(g) $\times 10^{20} \quad \mathrm{p}=1000-1500 \mathrm{dbar}$

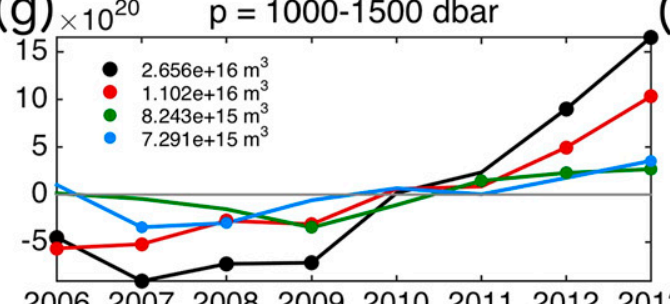

(h)

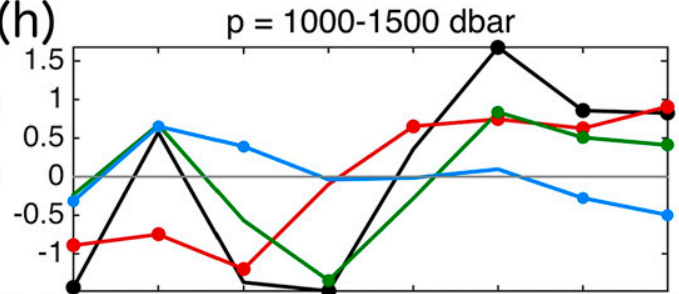

2006200720082009201020112012201320062007200820092010201120122013

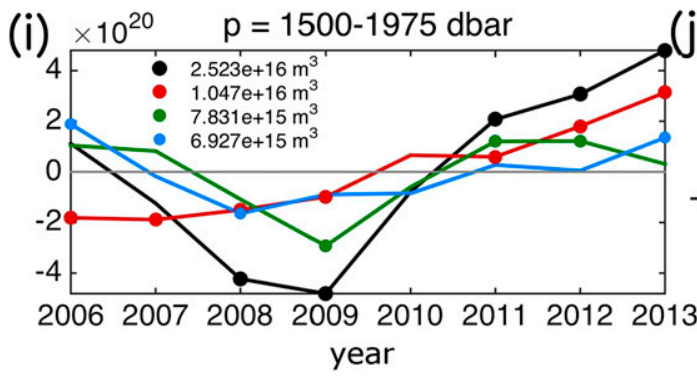

(j)

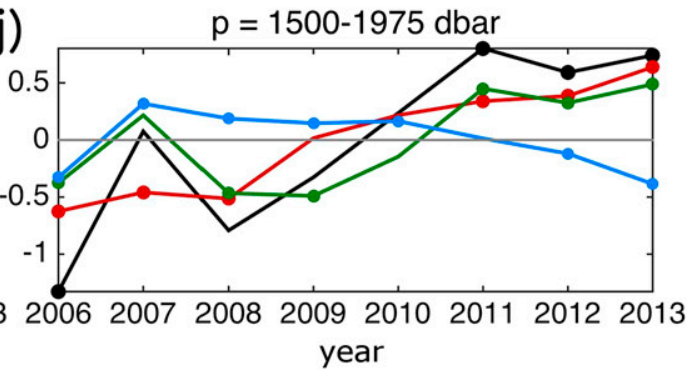

FIG. 9. Yearly (left) heat and (right) freshwater content anomalies from the 2006-13 time mean, in different regions of the Southern Ocean [legend in (b) and maps in Fig. 2b] and for different pressure ranges (tops and bottoms of pressure layers are indicated in the title). Dots signify that the yearly value is larger than its standard error. Freshwater values are in $\mathrm{cm}$, after normalizing the volume of freshwater by the area of the SO region $\left(6.001 \times 10^{13} \mathrm{~m}^{2}\right)$. The legend in the left panels indicates the ocean volume in each region.

isopycnal locations. Yet $\theta-S$ properties vary differently on the actual time-changing isopycnals (Fig. 12 vs Fig. 13), with potential density decreasing in time on the mean isopycnal location (Figs. 12i-l). The $\theta-S$ anomalies in Figs. 12a-h are not scaled by layer thickness but are consistent with heat and freshwater changes in Fig. 11, that is, overall $\theta$ increase (Figs. 12a-d) and $S$ decrease (Figs. 12e-h) during 2006-13 on most layers (except for salinity in the SAMW range). On the actual time-varying isopycnals, $\theta$ increases in time at all levels, only in the 

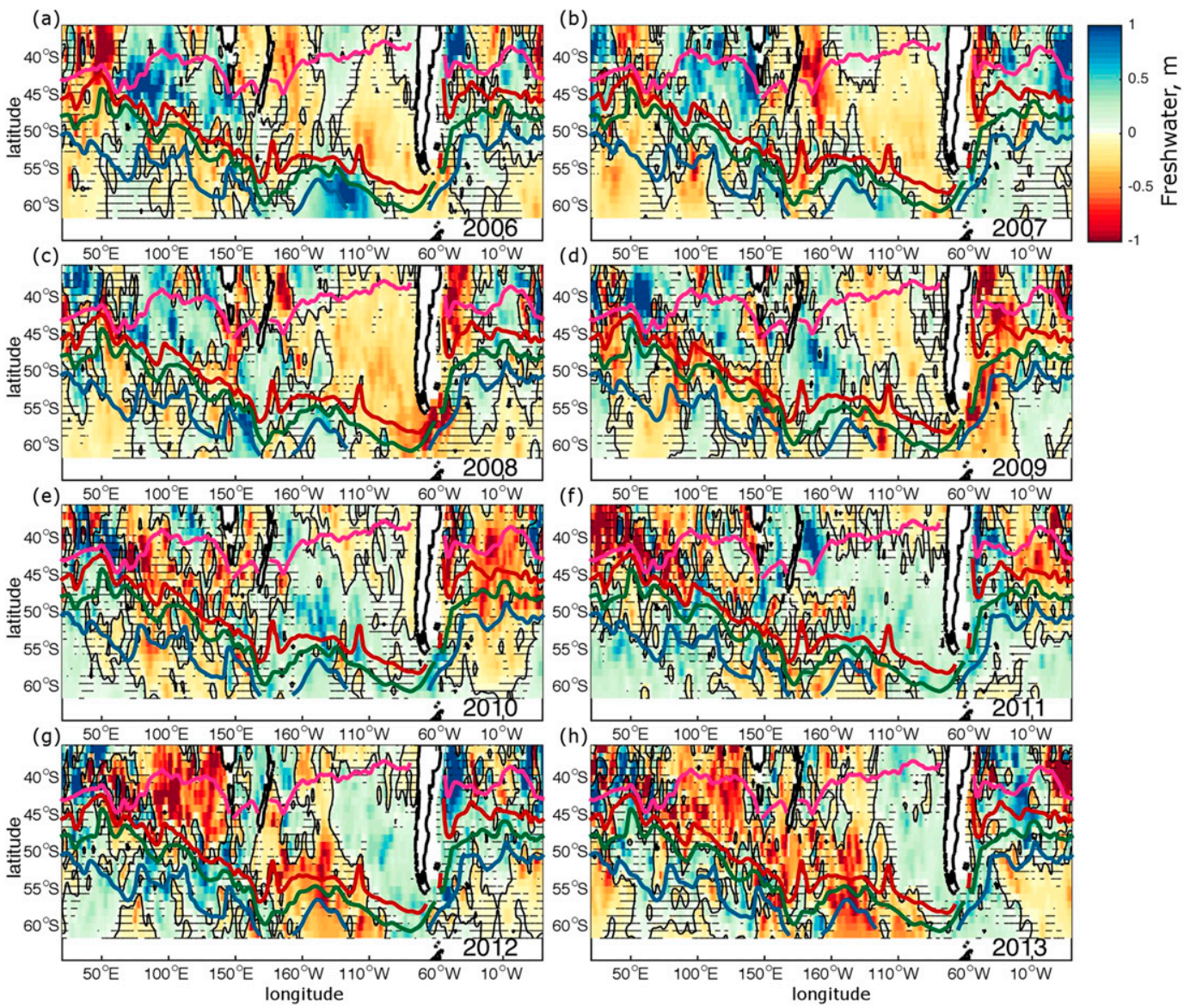

FIG. 10. Maps of yearly freshwater content $(\mathrm{m})$ anomalies from the 2006-13 time mean for the 0-1975-dbar pressure range, with zero contour (thin black line). Black dots signify that the yearly value is smaller than its standard error. Argo DH-based ACC fronts are indicated as thick lines as in Fig. 2b.

SAf.nPf and Pf.s regions (Figs. 13c-d), and decreases for $\sigma_{\theta}<27.3 \mathrm{~kg} \mathrm{~m}^{-3}$ in the SO and n.nSAf (Figs. 13a,b). Also, in SAf.nPf and Pf.s, salinity increases (rather than decreases) on most isopycnals (Figs. 13g,h), while, in the $\mathrm{SO}$, it does so only for $\sigma_{\theta}>27.3 \mathrm{~kg} \mathrm{~m}^{-3}$ (Fig. 13e). We find no significant salinity changes at such densities in n.nSAf (Fig. 13f).

\section{c. Ekman upwelling and downwelling and pressure changes on isopycnals}

We find an overall pressure increase on isopycnals in the Southern Ocean (Figs. 13i-1). In the SO, n.nSAf, and SAf.nPf regions, Argo pressure changes are consistent with a contribution from wind-forced vertical advection (i.e., Ekman upwelling and downwelling; Fig. 14), estimated from ECMWF ERA-Interim zonal and meridional momentum flux at the ocean-atmosphere interface. The agreement holds only in 2007-10 in n.nSAf, and it breaks down in Pf.s (not shown), where isopycnals shown in Fig. 14 (i.e., within the Southern Ocean Argo domain at each time step) are shallower and direct heat and freshwater exchanges with the atmosphere play a greater role than dynamics. In Pf.s, isopycnals are also steeper and carry ventilation to great depths. In general, when comparing between Argo pressure changes on isopycnals and wind forcing, diabatic contributions are not the only mechanism at play besides vertical advection (e.g., lateral motion of sloping isopycnals may also affect how pressure on isopycnals changes over time). These additional processes may explain some of the differences in pressure changes on isopycnals between Argo and the estimate from ECMWF ERA-Interim (i.e., sign and/or amplitude differences in Fig. 14), along with the uncertainty on the Ekman upwelling and downwelling from reanalysis and on the Argo fields (e.g., in 2006, the number of Argo floats in the SO is smaller than in later years). The analysis of the relative contribution of heave and water mass processes to $\theta-S$ property changes (Durack and Wijffels 2010) would be a valuable (future) addition to this work but is beyond the scope of the present study. 

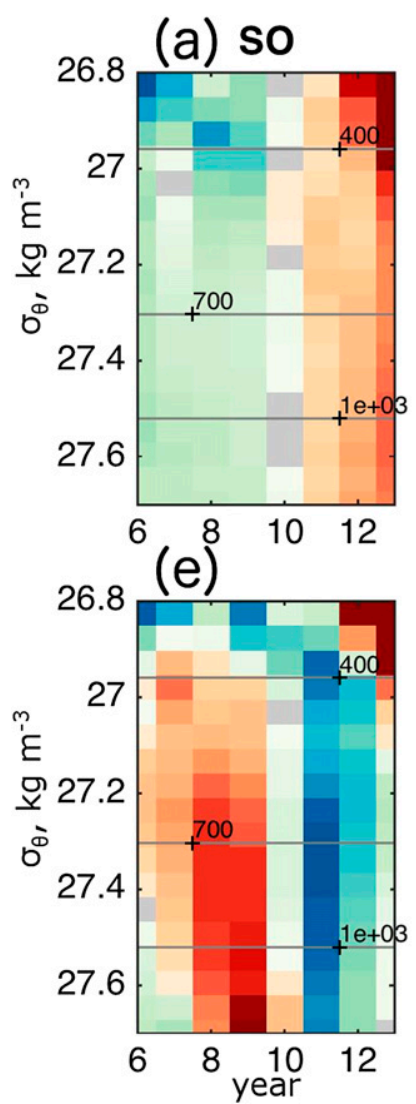
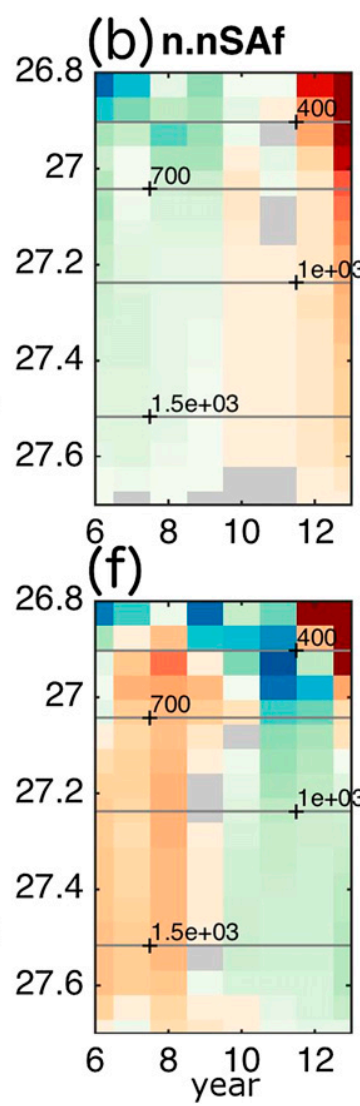
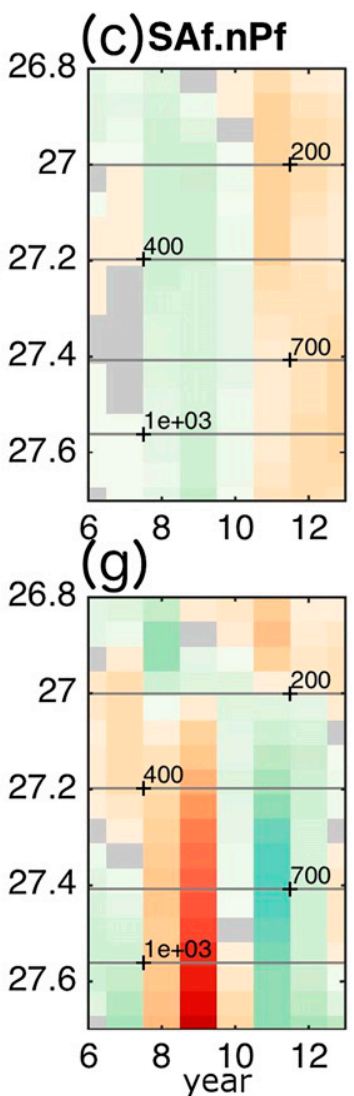
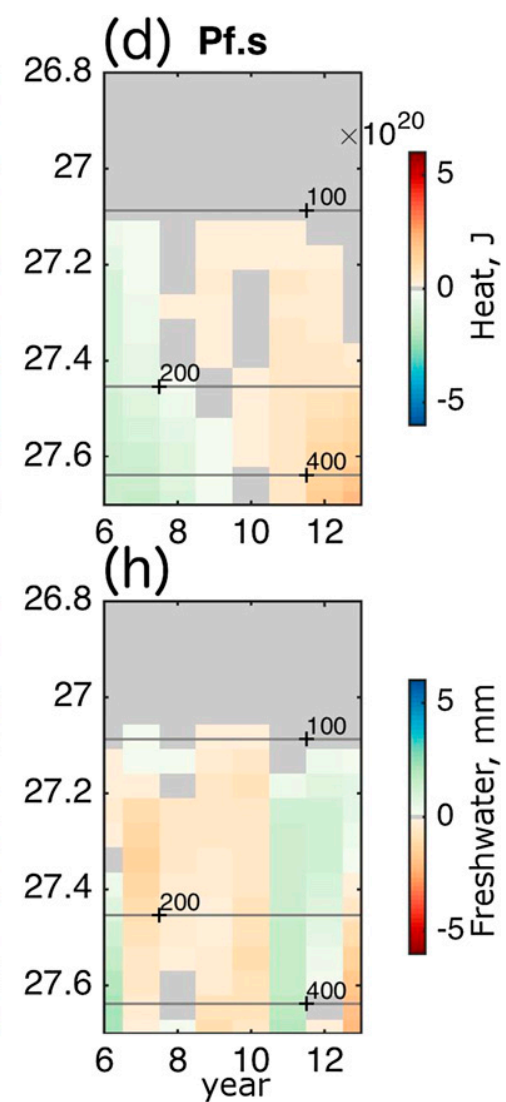

FIG. 11. Yearly (top) heat and (bottom) freshwater content anomalies from the 2006 to 2013 time mean in different regions of the Southern Ocean (same regions as in Fig. 9) and in $0.05 \mathrm{~kg} \mathrm{~m}^{-3}$ thick potential density classes ( $y$ axis). Values are based on the time-mean location of isopycnals. Freshwater values follow Fig. 9. Black contours: pressure on isopycnals. Years since 2000 are indicated on the $x$ axis.

\section{Summary and conclusions}

We use Argo's unprecedented (e.g., spatially distributed with no bias toward summer months) sampling of the Southern Ocean during 2006-13 to describe the recent positions of the Antarctic Circumpolar Current's Subantarctic and Polar Fronts equatorward of $\sim 60^{\circ} \mathrm{S}$. We compare and contrast two different methods for locating fronts in the same dataset. The first method [section $2 \mathrm{~b}(1)$ ] locates three fronts along dynamic height contours, each corresponding to a local maximum in vertically integrated shear (Fig. 1). We term these the Pf, sSAf, and nSAf (from south to north; Fig. 3 ). The second approach [section $2 b(2)$ ] locates the same fronts using specific features in the potential temperature field, consistent with subduction and/or shoaling of water masses (Table 1), following OWN95. The ACC fronts are associated with strong gradients in temperature and salinity and with deep-reaching jets (OWN95); hence, the two methods are in overall good agreement with each other. Argo DH frontal locations align well both with local maxima of the zonal and meridional geostrophic transport in the upper 1975 dbar (Fig. 4) and with $\theta$ properties that separate regions where the Southern Ocean water mass volume (within the Argo domain) peaks (Fig. 2), that is, regions with homogeneous $\theta$ properties. A local maximum in volume between the $\mathrm{Pf}$ and the sSAf is observed around $800 \mathrm{dbar}$ and deeper (Fig. 2) and corresponds to the Upper Circumpolar Deep Water. Another maximum is located between the sSAf and the nSAf, at depths shallower than $1000 \mathrm{dbar}$ (Fig. 2), and aligns with the freshest variety of Antarctic Intermediate Waters that begin to descend north of the Pf (not shown). The agreement between the two methods to locate the fronts also holds locally in most sectors of the Southern Ocean (Fig. 6) and for $\theta-S$ properties along the front (Fig. 7b). Yet the DH approach is preferable since $\mathrm{DH}$ is a vertically integrated quantity and hence not as affected by local phenomena as $\theta$ at a specific pressure level (e.g., SAMW formation in the eastern Pacific Ocean). Phenomenological ( $\theta$ based) characterizations that align best with the $\mathrm{DH}$ fronts follow an isotherm of the $\max (\theta)$ at $p \geq 800 \mathrm{dbar}$ and of $\theta$ at $p=400 \mathrm{dbar}$ for the Pf and SAf (sSAf and nSAf), 

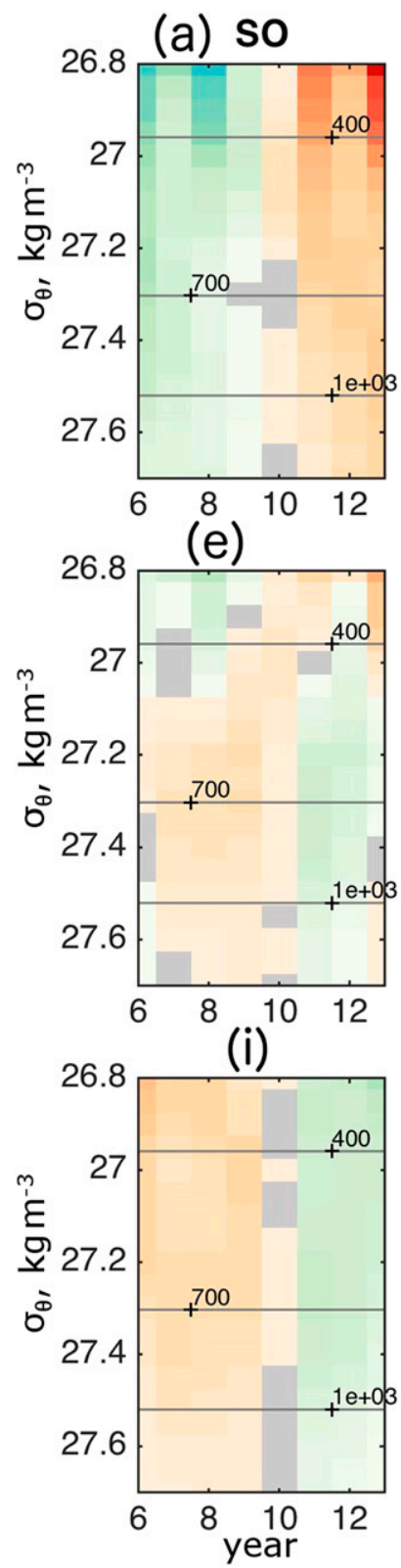

(b)n.nSAf
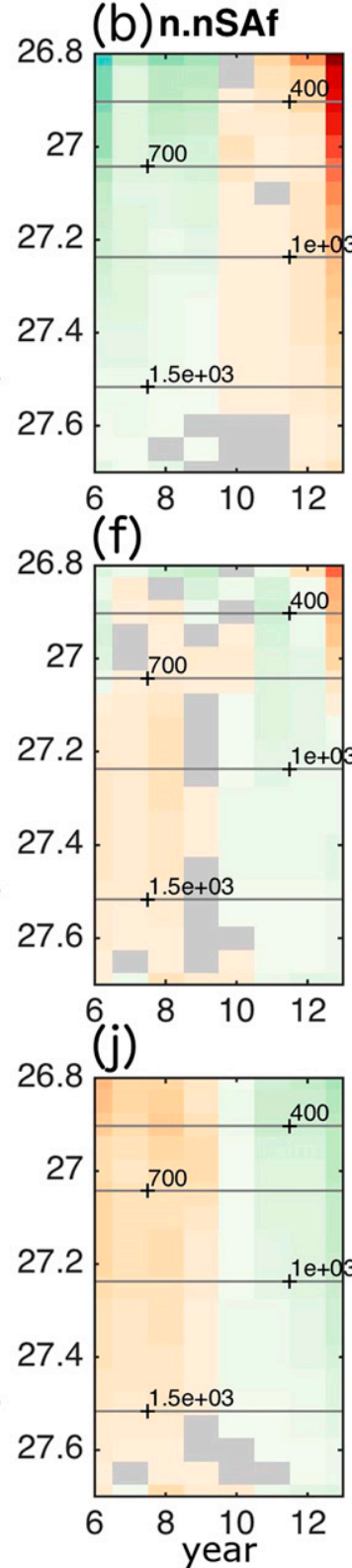
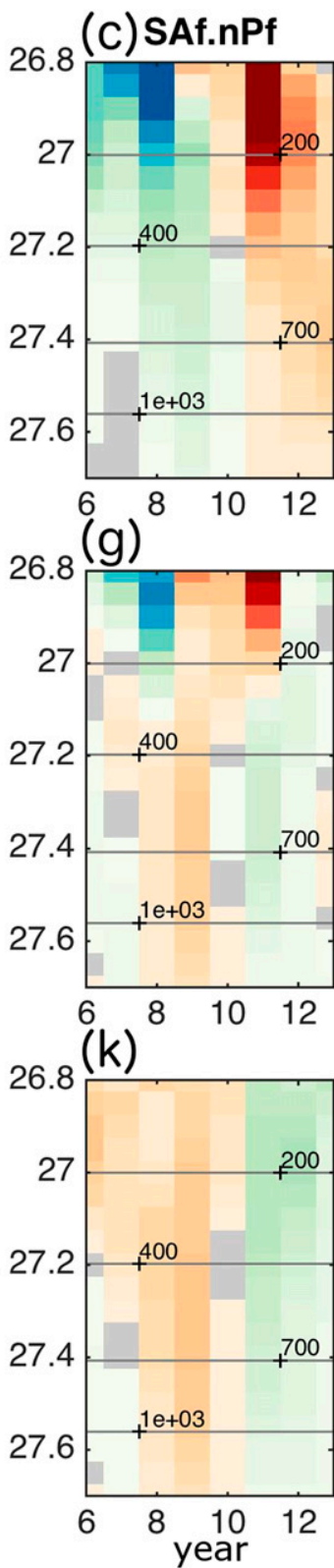
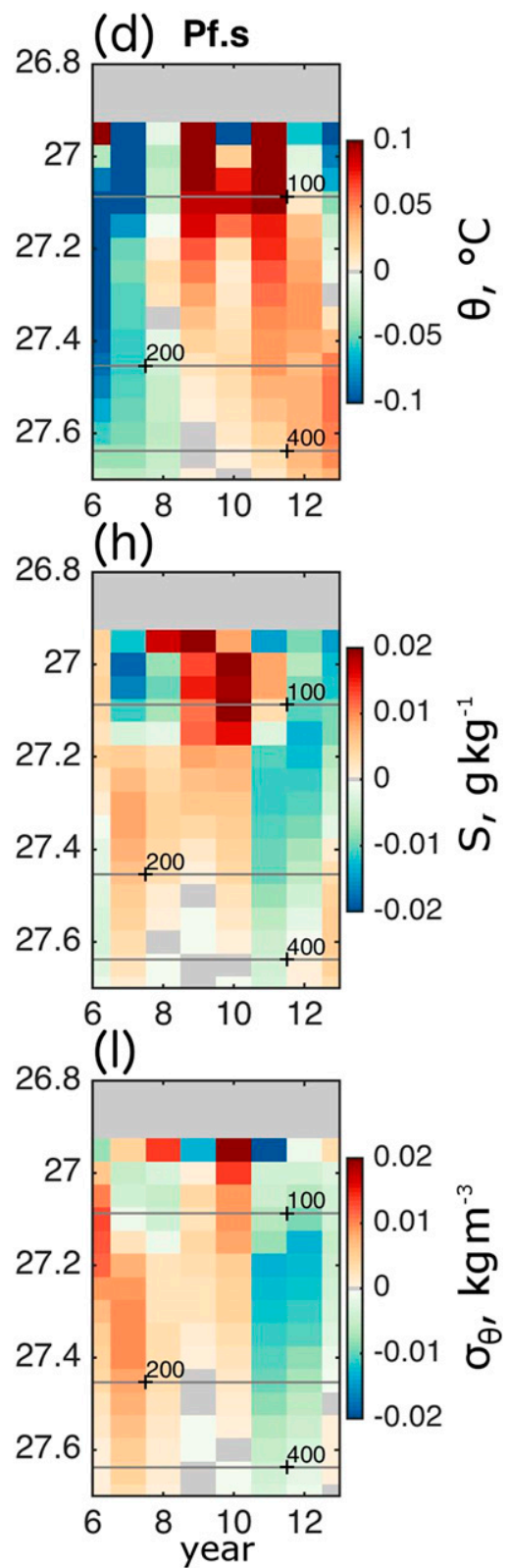

FIG. 12. Yearly anomalies from the 2006 to 2013 time mean of (top) potential temperature, (middle) salinity, and (bottom) potential density on the time-mean locations of a set of isopycnals $\left(y\right.$ axis; $\left.\mathrm{kg} \mathrm{m}^{-3}\right)$. Regions follow Fig. 9. Black contours: pressure on isopycnals. Years since 2000 are indicated on the $x$ axis.

respectively, and are still not consistent with the $\mathrm{DH}$ approach in a few regions, that is, the eastern Pacific for the nSAf and around $90^{\circ} \mathrm{E}$ and in the Atlantic basin for the sSAf and nSAf. In these sectors of the Southern Ocean, the combination of different $\theta-S$ criteria may be appropriate to locate the fronts more accurately. Also, the circumpolar $\theta^{*}$ value (of the isotherm at $p=$ 400 dbar) that aligns best with the DH-based sSAf is different from previous studies (Table 1). A main advantage in computing $\theta^{*}$ values along $\mathrm{DH}$-based (i.e., streamline based) fronts here resides in having both the streamfunction and the $\theta$ field from the same wellresolved (Argo) dataset and for the same time period (2006-13). Argo frontal locations are consistent overall with findings in Sokolov and Rintoul (2009a) and show local differences with OWN95 and other more recent analyses [section $2 b(1)$, e.g., at the Kerguelen and Campbell Plateaus, the Maurice Ewing Bank, and crossing the East Pacific Rise]. Our results focus on the time-mean frontal locations. As for movements of the 

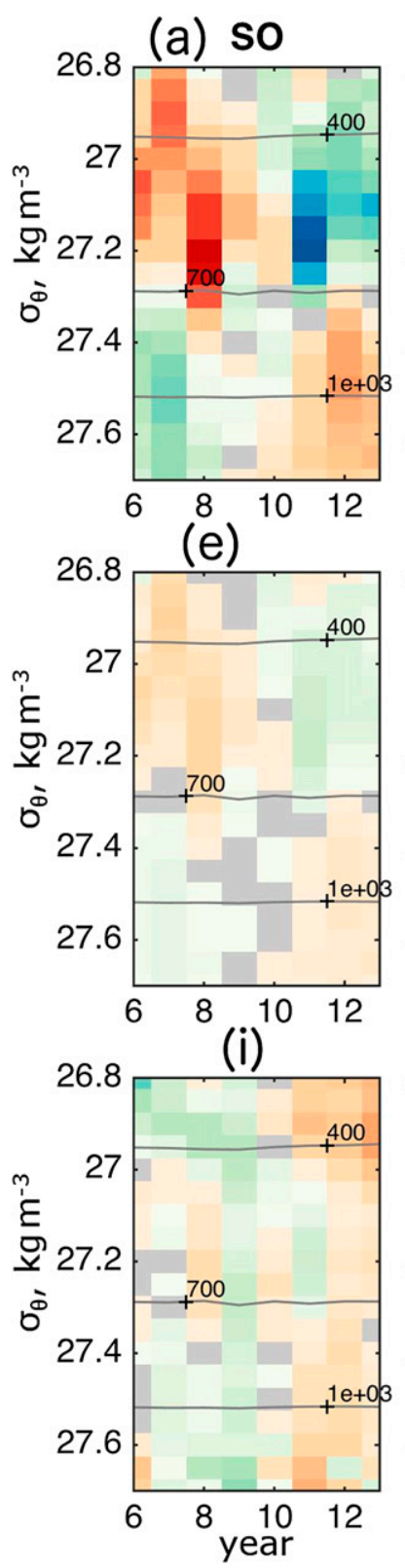
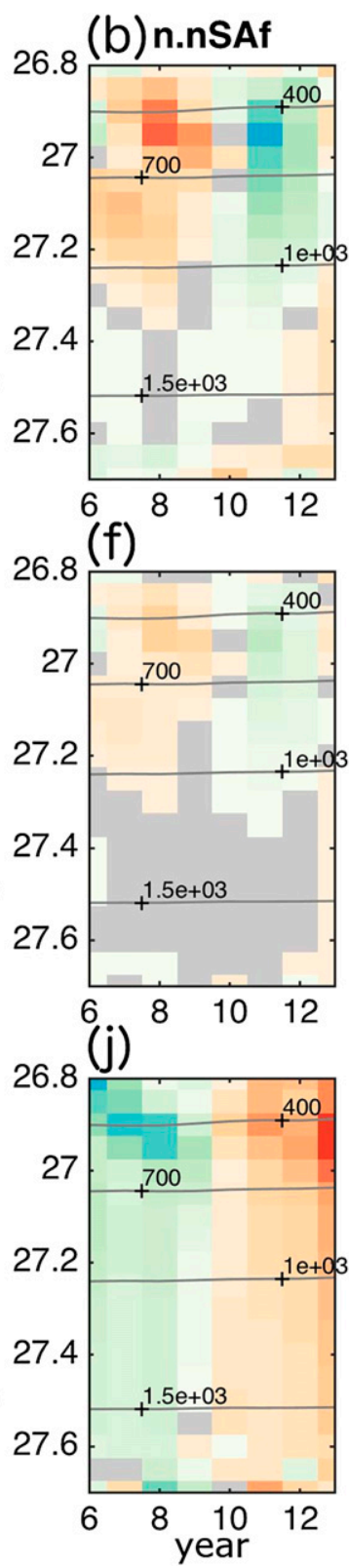
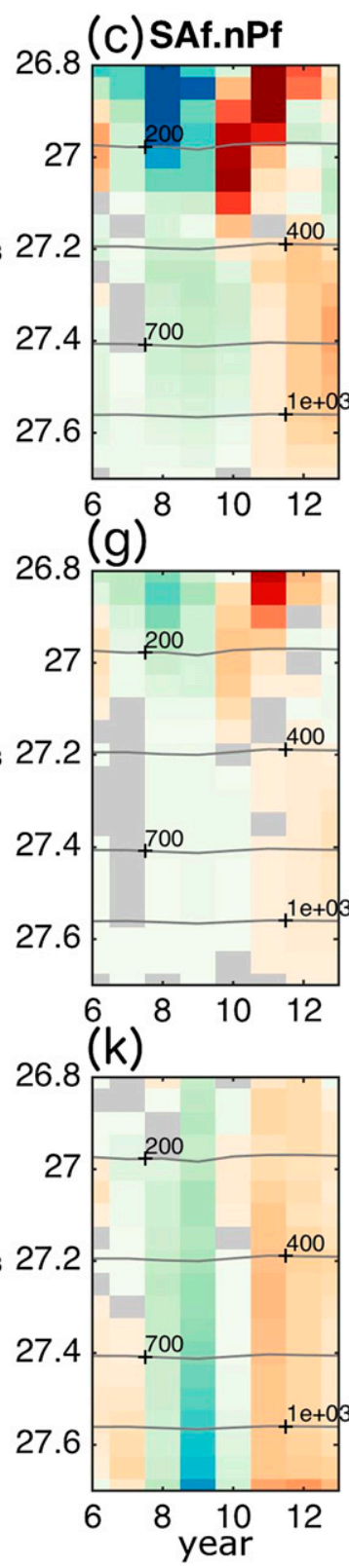
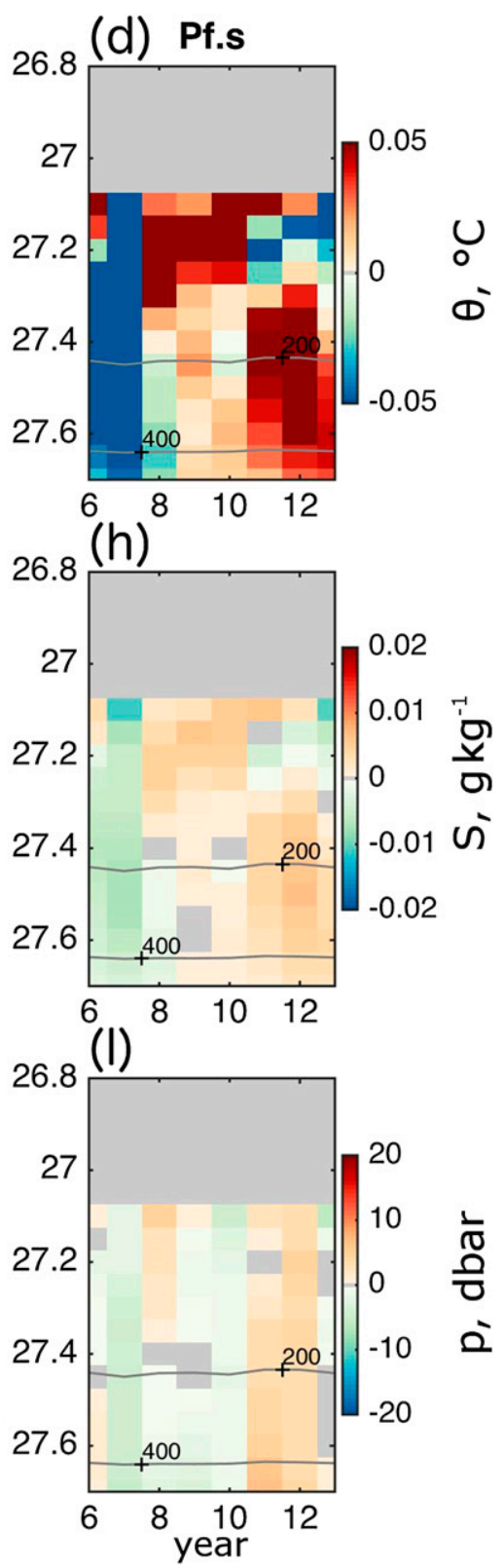

FIG. 13. Following Fig. 12, but on the actual (time varying) isopycnal locations. Bottom panels show pressure anomalies on isopycnals.

fronts in time, both a $\mathrm{DH}$ - and a $\theta$-based (contour) method would be biased by $\theta$ variability in the Southern Ocean (Graham et al. 2012; Thompson and Sallée 2012; De Boer et al. 2013; Gille 2014). Large-scale changes in DH and $\theta$ contours may, in fact, be due to a warming ocean more than localized shifts in frontal positions. Also, Argo resolution may not be appropriate to detect such changes. The method described recently by Shao et al. (2015) based on altimetry anomalies can be advantageous to track frontal movements in time.

We use Argo four-dimensional coverage of the Southern Ocean equatorward of $\sim 60^{\circ} \mathrm{S}$ to describe changes in heat and freshwater content in different regions of the Southern Ocean during 2006-13 with respect to the time-mean frontal location (section 4). Heat content increases from 2006 to 2013 in the upper $2000 \mathrm{dbar}$ of the SO region (i.e., south of the STf), with a signal that is mostly confined to the top $1000 \mathrm{dbar}$ and is weaker between 1000 and $1500 \mathrm{dbar}$. The FW anomaly (from the mean) in the top $2000 \mathrm{dbar}$ of the SO is negative in 2009 and 2013 and positive in 2011/12, with a decrease during the time period of interest in the upper $500 \mathrm{dbar}$ of the n.nSAf region (dominating the SO signal at those pressures) and an increase below $1000 \mathrm{dbar}$. Also, the yearly 
(a) Evolution of $\mathrm{p}_{\sigma}$ estimated from Ekman Upwelling

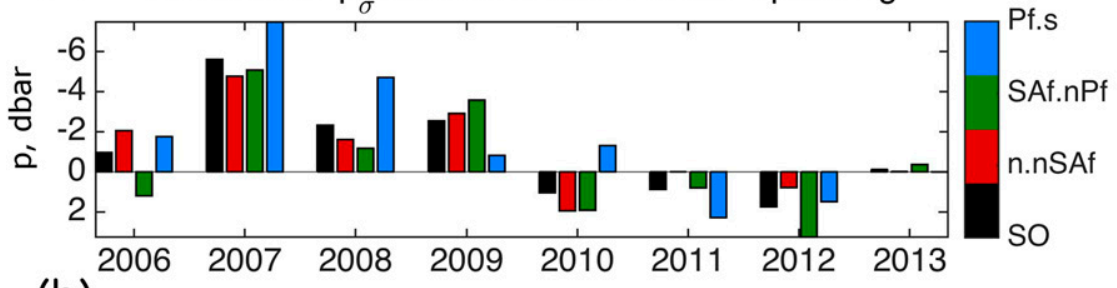

(b)

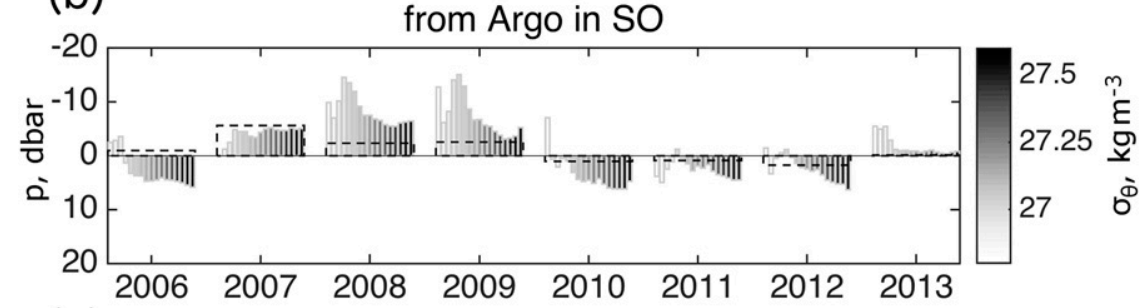

(c)

from Argo in n.nSAf

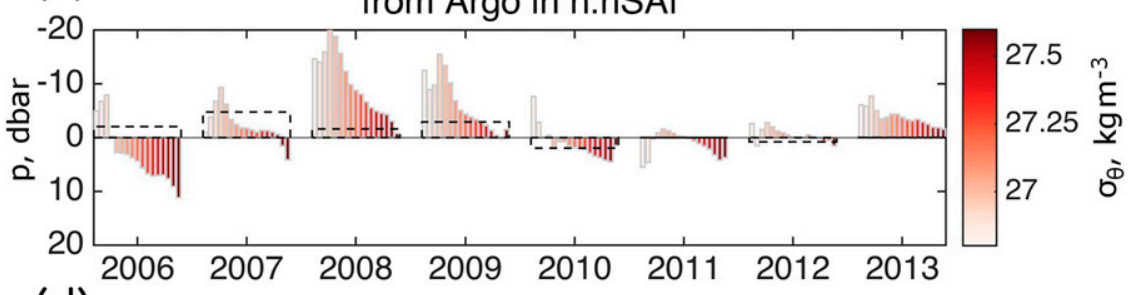

(d)

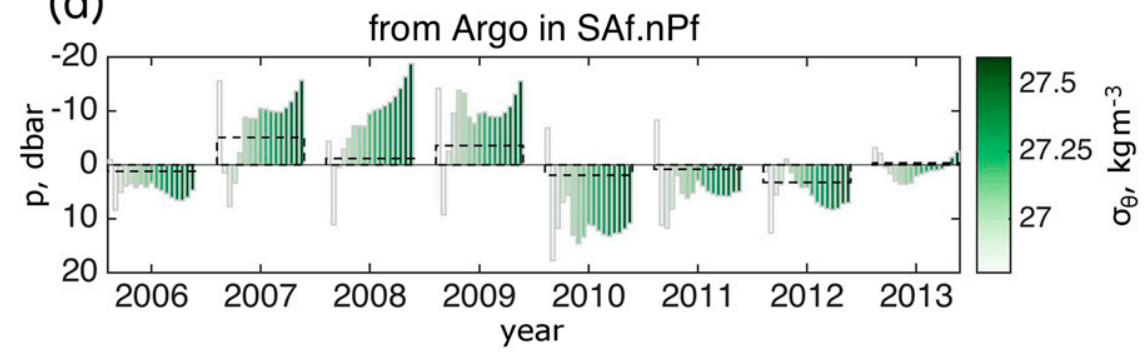

FIG. 14. Comparison of pressure changes on isopycnals (a) estimated from ECMWF ERAInterim wind stress curl (i.e., Ekman upwelling and downwelling) and (b)-(d) observed by Argo in different regions (following Fig. 9). Changes are indicated as the cumulative sum of monthly difference in pressure between month $i$ and month $i-1$ (or $d p$ ) since the beginning of 2006 (to the end of the year in the $x$ axis). In (b)-(d), light to dark shades are for lighter to denser isopycnals. Also, in (b)-(d), dashed lines indicate the estimate from Ekman upwelling and downwelling shown in (a).

freshwater anomaly (in the upper 1975 dbar; Fig. 9b) varies spatially in each region considered here (Fig. 10).

An overall increase of heat and freshwater content is observed for water masses in the range $26.8 \leq$ $\sigma_{\theta} \leq 27.7 \mathrm{~kg} \mathrm{~m}^{-3}$ (except for the SAMW with $26.8 \leq$ $\sigma_{\theta} \leq 26.9 \mathrm{~kg} \mathrm{~m}^{-3}$, where the FW anomaly is negative at the end of the time series and positive earlier), with positive (SO) FW anomalies also in $2006 / 07$ for $\sigma_{\theta}>27.45 \mathrm{~kg} \mathrm{~m}^{-3}$ (Fig. 11). This heat and FW estimate in potential density classes (i.e., for water masses) is based on the mean isopycnal location. Yet $\theta-S$ properties vary differently on the actual time-changing isopycnals (Fig. 12 vs
Fig. 13), with anomalies that are opposite in sign (compared to values on the time-mean isopycnal location) for $\theta$ and $S$ in the lighter and denser layers, respectively. This result suggests that heat and freshwater changes from using the mean isopycnal location may be partially related to isopycnal displacement.

We observe an overall pressure increase (in time) on isopycnals (Figs. 13i-1) consistent with wind-forced vertical advection by Ekman upwelling and downwelling (Fig. 14) in the SO, n.nSAf, and SAf.nPf regions. Such wind-forced vertical advection causes isopycnals to deepen in 2010-12, contributing to the observed ocean warming signal. 
Finally, ECMWF ERA-Interim SST shows a statistically significant linear decrease between 1979 and 2013 in the general ACC Pf regions at $140^{\circ}-170^{\circ} \mathrm{E}$ and $175^{\circ} \mathrm{E}-$ $120^{\circ} \mathrm{W}$ (not shown), consistent with a long-term local cooling of the upper ocean and with the $\min (\theta)$-based Argo Pf (with the $\theta^{*}$ value by OWN95) being equatorward of the Polar Front in OWN95 (Fig. 5) in these sectors of the Southern Ocean.

Acknowledgments. The Argo data used here were collected and are made freely available by the International Argo Program and by the national programs that contribute to it. The efforts of many international partners in planning and implementing the Argo array are gratefully acknowledged. ECMWF ERA-Interim momentum flux at the ocean-atmosphere interface and SST reanalysis fields used in this study have been obtained from the ECMWF data server. The objectively mapped Argo data were provided by John Gilson. DG was supported through a postdoctoral fellowship by the Joint Institute for the Study of the Atmosphere and Ocean (JISAO) under NOAA Cooperative Agreement NA15OAR4320063. GCJ is supported by NOAA Research and the NOAA Climate Observations Division. The statements, findings, conclusions, and recommendations herein are those of the authors and do not necessarily reflect the views of the National Oceanic and Atmospheric Administration or the Department of Commerce. Thanks to David Ferreira (U. Reading) and Matthew R. Mazloff (SIO) for the discussion about this work. Thanks to the two anonymous reviewers for providing valuable feedback.

\section{REFERENCES}

Alley, R. B., S. Anandakrishnan, K. Christianson, H. J. Horgan, A. Muto, B. R. Parizek, D. Pollard, and R. T. Walker, 2015: Oceanic forcing of ice-sheet retreat: West Antarctica and more. Annu. Rev. Earth Planet. Sci., 43, 207-231, doi:10.1146/ annurev-earth-060614-105344.

Anilkumar, N., and Coauthors, 2006: Fronts, water masses and heat content variability in the western Indian sector of the Southern Ocean during austral summer 2004. J. Mar. Syst., 63, 20-34, doi:10.1016/j.jmarsys.2006.04.009.

—, J. George, R. Chacko, N. Nuncio, and P. Sabu, 2015: Variability of fronts, fresh water input and chlorophyll in the Indian Ocean sector of the Southern Ocean. N. Z. J. Mar. Freshwater Res., 49, 20-40, doi:10.1080/00288330.2014.924972.

Aoki, S., N. L. Bindoff, and J. A. Church, 2005: Interdecadal water mass changes in the Southern Ocean between $30^{\circ} \mathrm{E}$ and $160^{\circ}$ E. Geophys. Res. Lett., 32, L07607, doi:10.1029/ 2004GL022220.

Belkin, I. M., and A. L. Gordon, 1996: Southern Ocean fronts from the Greenwich meridian to Tasmania. J. Geophys. Res., 101, 3675-3696, doi:10.1029/95JC02750.

Billany, W., S. Swart, J. Hermes, and C. J. C. Reason, 2010: Variability of the Southern Ocean fronts at the Greenwich meridian. J. Mar. Syst., 82, 304-310, doi:10.1016/j.jmarsys.2010.06.005.
Boehme, L., M. P. Meredith, S. E. Thorpe, M. Biuw, and M. Fedak, 2008: Antarctic Circumpolar Current frontal system in the South Atlantic: Monitoring using merged Argo and animalborne sensor data. J. Geophys. Res., 113, C09012, doi:10.1029/ 2007JC004647.

Böning, C. W., A. Dispert, M. Visbeck, S. R. Rintoul, and F. U. Schwarzkopf, 2008: The response of the Antarctic Circumpolar Current to recent climate change. Nat. Geosci., 1, 864869, doi:10.1038/ngeo362.

Boutin, J., L. Merlivat, C. Hénocq, N. Martin, and J. B. Sallée, 2008: Air-sea $\mathrm{CO}_{2}$ flux variability in frontal regions of the Southern Ocean from Carbon Interface Ocean Atmosphere drifters. Limnol. Oceanogr., 53, 2062-2079, doi:10.4319/lo.2008.53.5_part_2.2062.

Budillon, G., and S. Rintoul, 2003: Fronts and upper ocean thermal variability south of New Zealand. Antarct. Sci., 15, 141-152, doi:10.1017/S0954102003001135.

Chapman, C. C., 2014: Southern Ocean jets and how to find them: Improving and comparing common jet detection methods. J. Geophys. Res. Oceans, 119, 4318-4339, doi:10.1002/ 2014JC009810.

Close, S. E., A. C. N. Garabato, E. L. McDonagh, B. A. King, M. Biuw, and L. Boehme, 2013: Control of mode and intermediate water mass properties in Drake Passage by the Amundsen Sea low. J. Climate, 26, 5102-5123, doi:10.1175/JCLI-D-12-00346.1.

Cunningham, S., and M. Pavic, 2007: Surface geostrophic currents across the Antarctic Circumpolar Current in Drake Passage from 1992 to 2004. Prog. Oceanogr., 73, 296-310, doi:10.1016/ j.pocean.2006.07.010.

De Boer, A. M., R. M. Graham, M. D. Thomas, and K. E. Kohfeld, 2013: The control of the Southern Hemisphere westerlies on the position of the Subtropical Front. J. Geophys. Res. Oceans, 118, 5669-5675, doi:10.1002/jgrc.20407.

Ding, Q., E. J. Steig, D. S. Battisti, and M. Küttel, 2011: Winter warming in West Antarctica caused by central tropical Pacific warming. Nat. Geosci., 4, 398-403, doi:10.1038/ngeo1129.

Dong, S., J. Sprintall, and S. T. Gille, 2006: Location of the Antarctic Polar Front from AMSR-E satellite sea surface temperature measurements. J. Phys. Oceanogr., 36, 2075-2089, doi:10.1175/JPO2973.1.

Durack, P. J., and S. E. Wijffels, 2010: Fifty-year trends in global ocean salinities and their relationship to broad-scale warming. J. Climate, 23, 4342-4362, doi:10.1175/2010JCLI3377.1.

Firing, Y. L., T. K. Chereskin, and M. R. Mazloff, 2011: Vertical structure and transport of the Antarctic Circumpolar Current in Drake Passage from direct velocity observations. J. Geophys. Res. Oceans, 116, C08015, doi:10.1029/2011JC006999.

Gille, S. T., 1994: Mean sea surface height of the Antarctic Circumpolar Current from Geosat data: Method and application J. Geophys. Res., 99, 18255-18273, doi:10.1029/94JC01172.

—, 2008: Decadal-scale temperature trends in the Southern Hemisphere ocean. J. Climate, 21, 4749-4765, doi:10.1175/ 2008JCLI2131.1.

_ 2014: Meridional displacement of the Antarctic Circumpolar Current. Philos. Trans. Roy. Soc. London, A372, 20130273, doi:10.1098/rsta.2013.0273.

Graham, R. M., A. M. De Boer, K. J. Heywood, M. R. Chapman, and D. P. Stevens, 2012: Southern Ocean fronts: Controlled by wind or topography? J. Geophys. Res., 117, C08018, doi:10.1029/ 2012JC007887.

Hofmann, D. J., S. Oltmans, J. Harris, B. Johnson, and J. Lathrop, 1997: Ten years of ozonesonde measurements at the south pole: Implications for recovery of springtime Antarctic ozone. J. Geophys. Res., 102, 8931-8943, doi:10.1029/96JD03749. 
Holland, P. R., and R. Kwok, 2012: Wind-driven trends in Antarctic sea-ice drift. Nat. Geosci., 5, 872-875, doi:10.1038/ngeo1627.

Ito, T., M. Woloszyn, and M. Mazloff, 2010: Anthropogenic carbon dioxide transport in the Southern Ocean driven by Ekman flow. Nature, 463, 80-83, doi:10.1038/nature08687.

Jacobs, S. S., and C. F. Giulivi, 2010: Large multidecadal salinity trends near the Pacific-Antarctic continental margin. J. Climate, 23, 4508-4524, doi:10.1175/2010JCLI3284.1.

Johnson, G. C., 2008: Quantifying Antarctic Bottom Water and North Atlantic Deep Water volumes. J. Geophys. Res., 113, C05027, doi:10.1029/2007JC004477.

_ S. G. Purkey, and J. L. Bullister, 2008: Warming and freshening in the abyssal southeastern Indian Ocean. J. Climate, 21, 5351-5363, doi:10.1175/2008JCLI2384.1.

Kim, Y. S., and A. H. Orsi, 2014: On the variability of Antarctic Circumpolar Current fronts inferred from 1992-2011 altimetry. J. Phys. Oceanogr., 44, 3054-3071, doi:10.1175/JPO-D-13-0217.1.

Klatt, O., O. Boebel, and E. Fahrbach, 2007: A profiling float's sense of ice. J. Atmos. Oceanic Technol., 24, 1301-1308, doi:10.1175/JTECH2026.1.

Kobayashi, T., K. Mizuno, and T. Suga, 2012: Long-term variations of surface and intermediate waters in the southern Indian Ocean along $32^{\circ}$ S. J. Oceanogr., 68, 243-265, doi:10.1007/ s10872-011-0093-5.

Le Quéré, C., and Coauthors, 2009: Trends in the sources and sinks of carbon dioxide. Nat. Geosci., 2, 831-836, doi:10.1038/ngeo689.

Lumpkin, R., and K. Speer, 2007: Global ocean meridional overturning. J. Phys. Oceanogr., 37, 2550-2562, doi:10.1175/JPO3130.1.

Marshall, G. J., 2003: Trends in the southern annular mode from observations and reanalyses. J. Climate, 16, 4134-4143, doi:10.1175/ 1520-0442(2003)016<4134:TITSAM > 2.0.CO;2.

Marshall, J., and K. Speer, 2012: Closure of the meridional overturning circulation through Southern Ocean upwelling. Nat. Geosci., 5, 171-180, doi:10.1038/ngeo1391.

Meijers, A. J. S., N. L. Bindoff, and S. R. Rintoul, 2011: Frontal movements and property fluxes: Contributions to heat and freshwater trends in the Southern Ocean. J. Geophys. Res., 116, C08024, doi:10.1029/2010JC006832.

Naveira Garabato, A. C., L. Jullion, D. P. Stevens, K. J. Heywood, and B. A. King, 2009: Variability of Subantarctic Mode Water and Antarctic Intermediate Water in the Drake Passage during the late-twentieth and early-twenty-first centuries. J. Climate, 22, 3661-3688, doi:10.1175/2009JCLI2621.1.

Orsi, A. H., T. Whitworth, and W. D. Nowlin, 1995: On the meridional extent and fronts of the Antarctic Circumpolar Current. DeepSea Res. I, 42, 641-673, doi:10.1016/0967-0637(95)00021-W.

Paolo, F. S., H. A. Fricker, and L. Padman, 2015: Volume loss from Antarctic ice shelves is accelerating. Science, 348, 327-331, doi:10.1126/science.aaa0940.

Park, Y.-H., F. Vivier, F. Roquet, and E. Kestenare, 2009: Direct observations of the ACC transport across the Kerguelen Plateau. Geophys. Res. Lett., 36, L18603, doi:10.1029/2009GL039617.

—, I. Durand, E. Kestenare, G. Rougier, M. Zhou, F. D'Ovidio, C. Cotté, and J.-H. Lee, 2014: Polar Front around the Kerguelen Islands: An up-to-date determination and associated circulation of surface/subsurface waters. J. Geophys. Res. Oceans, 119, 6575-6592, doi:10.1002/2014JC010061.

Peterson, R. G., and T. Whitworth, 1989: The Subantarctic and Polar Fronts in relation to deep water masses through the southwestern Atlantic. J. Geophys. Res., 94, 10 817-10838, doi:10.1029/JC094iC08p10817.

Purkey, S. G., and G. C. Johnson, 2010: Warming of global abyssal and deep Southern Ocean waters between the 1990s and 2000s: Contributions to global heat and sea level rise budgets. J. Climate, 23, 6336-6351, doi:10.1175/2010JCLI3682.1.

and —, 2013: Antarctic Bottom Water warming and freshening: Contributions to sea level rise, ocean freshwater budgets, and global heat gain. J. Climate, 26, 6105-6122, doi:10.1175/JCLI-D-12-00834.1.

Renault, A., C. Provost, N. Sennéchael, N. Barré, and A. Kartavtseff, 2011: Two full-depth velocity sections in the Drake Passage in 2006-Transport estimates. Deep-Sea Res. II, 58, 2572-2591, doi:10.1016/j.dsr2.2011.01.004.

Rignot, E., S. Jacobs, J. Mouginot, and B. Scheuchl, 2013: Ice-shelf melting around Antarctica. Science, 341, 266-270, doi:10.1126/ science.1235798.

— J. Mouginot, M. Morlighem, H. Seroussi, and B. Scheuchl, 2014: Widespread, rapid grounding line retreat of Pine Island, Thwaites, Smith, and Kohler Glaciers, West Antarctica, from 1992 to 2011. Geophys. Res. Lett., 41, 3502-3509, doi:10.1002/ 2014GL060140.

Rintoul, S. R., C. Hughes, and D. Olbers, 2001: The Antarctic Circumpolar System. Ocean Circulation and Climate, G. Siedler, J. Church, and J. Gould, Eds., Academic Press, 271-302.

Roemmich, D., and J. Gilson, 2009: The 2004-2008 mean and annual cycle of temperature, salinity, and steric height in the global ocean from the Argo program. Prog. Oceanogr., 82, 81100, doi:10.1016/j.pocean.2009.03.004.

, and Coauthors, 2009: The Argo program: Observing the global oceans with profiling floats. Oceanography, 22, 34-43, doi:10.5670/oceanog.2009.36.

—, J. Church, J. Gilson, D. Monselesan, P. Sutton, and S. Wijffels, 2015: Unabated planetary warming and its ocean structure since 2006. Nat. Climate Change, 5, 240-245, doi:10.1038/ nclimate2513.

Sabine, C. L., 2004: The oceanic sink for anthropogenic $\mathrm{CO}_{2}$. Science, 305, 367-371, doi:10.1126/science.1097403.

Sallée, J. B., K. Speer, and R. Morrow, 2008: Response of the Antarctic Circumpolar Current to atmospheric variability. J. Climate, 21, 3020-3039, doi:10.1175/2007JCLI1702.1.

_ , R. J. Matear, S. R. Rintoul, and A. Lenton, 2012: Localized subduction of anthropogenic carbon dioxide in the Southern Hemisphere oceans. Nat. Geosci., 5, 579-584, doi:10.1038/ ngeo1523.

Schmidtko, S., and G. C. Johnson, 2012: Multidecadal warming and shoaling of Antarctic Intermediate Water. J. Climate, 25, 207221, doi:10.1175/JCLI-D-11-00021.1.

, K. J. Heywood, A. F. Thompson, and S. Aoki, 2014: Multidecadal warming of Antarctic waters. Science, 346, 1227-1231, doi:10.1126/science.1256117.

Shao, A. E., S. T. Gille, S. Mecking, and L. Thompson, 2015: Properties of the Subantarctic Front and Polar Front from the skewness of sea level anomaly. J. Geophys. Res. Oceans, 120, 5179-5193, doi:10.1002/2015JC010723.

Sokolov, S., and S. R. Rintoul, 2002: Structure of Southern Ocean fronts at $140^{\circ}$ E. J. Mar. Syst., 37, 151-184, doi:10.1016/ S0924-7963(02)00200-2.

- and _- 2007: Multiple jets of the Antarctic Circumpolar Current south of Australia. J. Phys. Oceanogr., 37, 1394-1412, doi:10.1175/JPO3111.1.

, and - 2009a: Circumpolar structure and distribution of the Antarctic Circumpolar Current fronts: 1. Mean circumpolar paths. J. Geophys. Res., 114, C11018, doi:10.1029/ 2008JC005108.

, and $-2009 \mathrm{~b}$ : Circumpolar structure and distribution of the Antarctic Circumpolar Current fronts: 2. Variability and 
relationship to sea surface height. J. Geophys. Res., 114, C11019, doi:10.1029/2008JC005248.

Sparrow, M. M., K. K. Heywood, J. Brown, and D. Stevens, 1996: Current structure of the south Indian Ocean. J. Geophys. Res., 101, 6377-6391, doi:10.1029/95JC03750.

Sprintall, J., 2008: Long-term trends and interannual variability of temperature in Drake Passage. Prog. Oceanogr., 77, 316-330, doi:10.1016/j.pocean.2006.06.004.

Sutton, P., and D. Roemmich, 2011: Decadal steric and sea surface height changes in the Southern Hemisphere. Geophys. Res. Lett., 38, L08604, doi:10.1029/2011GL046802.

Swart, S., and S. Speich, 2010: An altimetry-based gravest empirical mode south of Africa: 2. Dynamic nature of the Antarctic Circumpolar Current fronts. J. Geophys. Res., 115, C03003, doi:10.1029/2009JC005300.

Tarakanov, R. Y., 2011: Southern jets of the Antarctic Circumpolar Current in the eastern Pacific Antarctic. Oceanology, 51, 588598, doi:10.1134/S0001437011040175.

, 2014: Jets of the Antarctic Circumpolar Current in the central part of the Drake Passage based on the survey data in October-November of 2008. Oceanology, 54,1-7, doi:10.1134/ S000143701401010X.

Thompson, A. F., and J.-B. Sallée, 2012: Jets and topography: Jet transitions and the impact on transport in the Antarctic Circumpolar Current. J. Phys. Oceanogr., 42, 956-972, doi:10.1175/ JPO-D-11-0135.1.
P. H. Haynes, C. Wilson, and K. J. Richards, 2010: Rapid Southern Ocean front transitions in an eddy-resolving ocean GCM. Geophys. Res. Lett., 37, L23602, doi:10.1029/ 2010GL045386.

Thompson, D. W. J., S. Solomon, P. J. Kushner, M. H. England, K. M. Grise, and D. J. Karoly, 2011: Signatures of the Antarctic ozone hole in Southern Hemisphere surface climate change. Nat. Geosci., 4, 741-749, doi:10.1038/ngeo1296.

Thompson, K. R., and E. Demirov, 2006: Skewness of sea level variability of the world's oceans. J. Geophys. Res., 111, C05005, doi:10.1029/2004JC002839.

Van Sebille, E., P. Spence, M. R. Mazloff, M. H. England, S. R. Rintoul, and O. A. Saenko, 2013: Abyssal connections of Antarctic Bottom Water in a Southern Ocean State Estimate. Geophys. Res. Lett., 40, 2177-2182, doi:10.1002/ grl.50483.

Watson, A. J., M. P. Meredith, and J. C. Marshall, 2014: The Southern Ocean, carbon and climate. Philos. Trans. Roy. Soc. London, A372, 20130057, doi:10.1098/rsta.2013.0057.

WMO, 2011: Scientific assessment of ozone depletion: 2010. Global Ozone Research and Monitoring Project Rep. 52, $516 \mathrm{pp}$.

Yang, X. Y., and Z. He, 2014: Decadal change of Antarctic Intermediate Water in the region of Brazil and Malvinas Confluence. Deep-Sea Res. I, 88, 1-7, doi:10.1016/ j.dsr.2014.02.007. 